\title{
The Pharmaceuticals Using for COVID-19 Patients and in Silico Natural Product Studies about COVID-19
}

\author{
Sibel Avunduk* \\ Medical Laboratory Techniques Programme, Vocational College of Medical Health, Turkey \\ *Corresponding author: Sibel Avunduk, Medical Laboratory Techniques Programme, Vocational College of Medical \\ Health, Mugla University, Turkey
}

\section{ARTICLE INFO}

Received: 崫 December 16, 2020

Published: 慧 December 23, 2020

Citation: Sibel Avunduk. The Pharmaceuticals Using for COVID-19 Patients and in Silico Natural Product Studies about COVID-19. Biomed J Sci \& Tech Res 32(5)-2020. BJSTR. MS.ID.005318.

\section{ABSTRACT}

The COVID-19 pandemic without a doubt will be regarded the biggest epidemic which is still going on to impact the whole world in the humanity history. That's why it is imperative to discover new therapeutic agents and vaccines by the scientific world. This review especially includes the studies and reviews about therapy protocols used in the cure of COVID-19, also the papers about in silico researches on phytochemical compounds and the other marketed drugs. The aim of the review to summarize the antiviral drugs experienced in COVID-19 cure during the first peak of the pandemic; compile and inform the in silico studies focused on the plant sourced compounds and repurposed drugs. The review will generate a guiding source to further in vitro and in vivo research in the way of looking for effective compounds to combat COVID-19 pandemic.

\section{Introduction}

In these bizarre moments, the Coronavirus infection 2019 (COVID-19) pandemic has had a serious impact globally. Most countries have enforced strict 'lock- down', and social distancing and isolation of the old and vulnerable are considered [1]. COVID-19 is lead to SARS-CoV-2, which is a positive-sense single-stranded RNA virus. The infection is frequently perplexed by a obvious inflammatory response, which, in order, can beget multiorgan malfunction, respiratory collapse, and death [2]. There is no accepted practical cure for SARS-CoV-2 epidemic, showing an acute and crucial required for novel drugs or vaccines [3,4]. SARS-CoV-2 is commonly less pathogenic than SARS-CoV, much less pathogenic than the Middle East respiratory syndrome MERS-CoV, but more pathogenic than practically powerless HCoV-OC43, HCoV-HKU1, HCoV-229E, and HCoV- NL63. The announced case-fatality rate of COVID-19 is $\% 3 \%$ and is so rather low as compared with SARS $30 \%$ (Table 1). Nonetheless, the transmission rate (TR) (number of newly infected people per infected person) of 2.5 to 3 is high and clarifies the danger of the current pandemic. For comparison, the TR of the yearly typical cold is less than 1.4 [5]. In December 2019, an abnormal viral pneumonia induce to a novel coronavirus was diagnosed in Wuhan, China [6]. Within months, the disease, later called coronavirus disease 2019 (COVID-19) by the World Health
Organization (WHO), had dispersed worldwide and turn into a universal health emergency. As stated in WHO, as of June 09, 2020, the number of accepted cases was over 7,039,918 and the number of deaths more than $404396[6,7]$.

\section{The Drugs Using COVID-19 Treatment}

\section{Antiviral Agents}

a. IFN- $\alpha$ : Type I interferons, along with IFN- $\alpha$ and IFN- $\beta$, have wide-spectrum antiviral properties [8]. IFN- $\alpha$ can precisely inhibit virus replication or can manage antiviral effects by stimulating inherited or adaptive immunity $[9,10]$. Clinical examination in animals and humans exhibited that MERS-CoV infections were arbitrated by both virus replication and host inflammatory responses. Those findings bring about analysis of combination cures that constituted type I interferon (IFN-I) and IFN-II. Interferon beta (IFN- $\beta$ ) showed the best effectiveness, with EC50s of 1.37 to $17 \mathrm{IU} / \mathrm{ml}$, for decreasing MERS-CoV replication in tissue culture $[11,12]$. Chiefly, another controlled trial was begun in China to examine the efficacy of LPV/RTV and IFN-a $\alpha 2 b$ in hospitalized patients with SARS-CoV-2 infections (Clinical Trials registration no. ChiCTR2000029308) [13]. 
b. Lopinavir/Ritonavir: Lopinavir was early athorized in the United States in 2000 for the medication of HIV infection [14]. It is a protease inhibitor and is generally applied in together with ritonavir to increase its half-life by the inhibition of cytochrome P450 [15]. Presently, the drug has been utilized in the clinical cure of COVID-19 at a quantitiy of $400 \mathrm{mg} / 100 \mathrm{mg}$ for adults two times in a day, and the way of healing does not dure more than 10 days [16]. Notwithstanding, this treatment has definite toxic and adverse effects on the healing of COVID-19. Thus, its safety and potency need further investigation. Newly, a number of clinical studies have exerts that lopinavir/ritonavir cure has no significant power $[10,17,18]$. Lopinavir/Ritonavir (LPV/r), also acknowledged as Kaletra, is an oral mixture agent for healing HIVaccepted by the FDA, which has displayed anti-coronavirus efficacy in researchs of SARS and MERS [19-22]. As a new protease inhibitor, LPV/r breaks off viral nucleic acid replication via inhibition of 3CLpro [23,24]. Even though more clinical trials are ongoing lopinavir/ritonavir, recent data do not hold lopinavir/ritonavir in COVID-19 cure. This because of important drug on drug interactions and their hidden adverse reactions. In accordance with a current RCT, about $50 \%$ of patients administered with lopinavir/ritonavir observed at least one side effect and $14 \%$ of patients had to cut off the therapy [25] The prime adverse reactions of lopinavir/ritonavir consist of the gastrointestinal maladies (up to 30\%) and hepatotoxicity (between $2 \%$ and $10 \%$ ) [26]. More severe side reactions are defined by hepatotoxicity, pancreatitis, abnormalities in cardiac conduction $[25,27,28]$.

\section{c. Ribavirin}

Ribavirin is a purine nucleoside derivative with a extensivespectrum antiviral power [29]. It is used primarily to heal respiratory syncytial virus infection [30] and in mixed with interferon for hepatitis C [31]. Ribavirin was broadly used in 2003 to heal SARS- CoV infection, but when utilized alone, it implayed to have no action and generated importanthemolysis in many sufferers [32-35]. When ribavirin was blended with IFN- $\beta$, it had favorable antiviral action in in vitro assays [36]. Preperatory in vitro assay results show that ribavirin can deactivate SARS-CoV-2 in a human cell line. In the most recent "Diagnosis and Treatment Protocol for Novel Coronavirus Pneumonia", it is advised to administer ribavirin at a shot of $500 \mathrm{mg}$ each time for adults and in combination with interferon or lopinavir/ritonavir, with 2-3 intravenous infusions every day. The course of healing does not exceed 10 days $[16,10]$.

\section{d. Arbidol}

Umifenovir (ArbidolTM), (ethyl-6-bromo-4-[(dimethylamino) me- thyl]-5-hydroxy-1-methyl-2 [(phenylthio)methyl]-indole3-carboxylate hydrochloride monohydrate), (CAS number: 131707-25-0), is a little indole-derivate compound manufactured by JSC Pharmstandard, Russia $[37,38]$. Arbidol is a non-nucleoside wide-spectrum antiviral medicine for upper respiratory tract infections generated by influenza A and B viruses, and it was first accepted Russia [37]. It can prevent the adhesion of viruses to host cells and impede them from infesting human cells [39]. Concurrent, it can boost the synthesis of interferon, which can inhibit influenza virus invasion and heal influenza virus infection [40]. As represented in the latest "Diagnosis and Treatment Protocol for Novel Coronavirus Pneumonia", arbidol is utilized at a dose of $200 \mathrm{mg}$ for adults three times day to day, and the line of cure does not outpace 10 days $[10,16]$. In a clinical pilot experiment handled in January 2020 in Wuhan, China, 36 sufferers with COVID-19 disease took $400 \mathrm{mg}$ umifenovir three times a day for 9 days; 31 untreated COVID-19 patients played as a control group [41]. In this trial, healing with umifenovir displayed a tendency to lessen viral load detected by RT-PCR, and reduced mortality (0 \% vs. $16 \%$ ), as compared to the control group [41].

In a single-center, retrospective cohort trial operated in February 2020 in Guangdong, China, 16 sufferers with COVID-19 bug received orally $200 \mathrm{mg}$ umifenovir each $8 \mathrm{~h}$ plus lopinavir $(400 \mathrm{mg}) /$ ritonavir $(100 \mathrm{mg}$ ) every $12 \mathrm{~h}$ for 5-21 days; seventeen COVID-19 cases got lopinavir (400mg)/ritonavir (100mg) every $12 \mathrm{~h}$ and acted as a control group [42]. After 14 days of healing, determination of SARS-COV-2 by RT-PCR was negative in $94 \%$ of the umifenovir- cured patients vs. $53 \%$ in the control group, and the chest computed tomography scans were developing for $69 \%$ of the umifenovir-cured patients vs. $29 \%$ in the control group [42]. In view of these auspicious clinical outcomes, clinical studies with umifenovir only or in combination with lopinavir/ ritonavir, chloroquine phosphate or carrimycin have been currently commenced in China [38,43-46].

\section{e. Favipiravir}

Favipiravir (AviganTM), (T-705), (6-fluoro-3-hydroxy-2pyrazinecarboxamide), (CAS number: 259793-96-9), is an oral pyrazinecarboxamide analogue and guanine derivative advanced by Toyama Chemical, Japan that choosy and powerfully inhibits the RNA- dependent RNA polymerase (RdRp) of RNA viruses and activates lethal RNA transversion mutations, by that producing a useless virus phenotype [38,47-49]. Favipiravir have [50,51] a capability to inhibit RNA-dependent polymerase [52] and was accepted for commerce in Japan in 2014. It is applied for antiviral cure of influenza A and B [52] and can powerfully inhibit Ebola virus, yellow fever virus [53], etc. In vitro assays have demonstrated that favipiravir is active for COVID-19 and that its EC50 is $61.88 \mu \mathrm{M}$ [54]. Till today, some clinical trials of favipiravir in the healing of COVID-19 have been performed in China. Current clinical researches have found that contrasted with the antiviral medicine arbidol, the clinical action of favipiravir is more serious. Nucleic acid positive-to-negative time, mean antipyretic time and cough remission time were all better than those of the arbidol group $[10,18]$. Favipiravir was able to blockade the RDRP of SARS-CoV and MERS in vitro. Because of the high resemblence of SARS- CoV-2 genome with SARS-CoV [55] this treatment is believed a potential 
candidate for COVID-19, though in vitro efficacy on SARS-CoV-2 has not been analyzed yet [56]. Favipiravir is now being evaluated in RCTs calling up patients with COVID-19, to figüre out its efficacy when mixed with interferon- $\alpha$ or baloxavir marboxil (approved InfV inhibitor) (ChiCTR2000029548) [57].

\section{f. Remdesivir (GS-5734)}

Remdesivir (GS-5734), (CAS number: 1809249-37-3), is a novel tiny-molecule adenine nucleotide analogue antiviral compound that has exhibited potency against Ebola virus in rhesus monkeys. Remdesivir shows antiviral activity against other single stranded RNA viruses, containing filoviruses, pneumoviruses, paramyxoviruses, and the coronaviruses MERS-CoV and SARSCoV [38,58-60]. Remdesivir was first utilized to treat Ebola virus, and it has achieved phase 2 clinical trials [61]. As a nucleoside derivative, it can reach out with $\operatorname{RdRp}[62,63]$, and the triphosphate form of remdesivir will fight with adenosine triphosphate, causing to slowed chain termination and prohibiting viral replication and transcription [64]. According to the above proof, remdesivir has been practiced to cure SARS-CoV-2, and in vitro researches showed that remdesivir has a satisfying inhibitory action on SARS-CoV-2, with an EC50 of $0.77 \mu \mathrm{M}$ [54]. Currently, the first COVID-19 victim in USA was cured with remdesivir on the $7^{\text {th }}$ day of hospitalization, and their clinical signs were made better significantly $[10,65]$. In in-vitro study, the EC50 of Remdesivir against SARS-COV-2 in Vero E6 cells was $0.77 \mu \mathrm{M}$ and the EC90 was $1.76 \mu \mathrm{M}$ [66]. The symptoms of a COVID-19 positive patient in Washington, USA cured with Remdesivir improved and no noteworthy side effects were observed. Eventually, 13 days after treatment with Remdesivir the outcome of real-time RT-PCR analysis from the oropharyngeal swab was negative for SARS-CoV-2 $[67,68]$.

\section{g. Chloroquine Phosphate}

Chloroquine phosphate (ResochinTM) and its derivative hydroxychloroquine (QuensylTM, PlaquenilTM, HydroquinTM, DolquineTM, QuinoricTM) have been practiced for ten years for the prophylaxis and healing of malaria and for the cure of chronic Q fever and various autoimmune illnesses [69] and have newly been indicated as promising broad-spectrum antiviral medicine $[38,70,71]$. Chloroquine phosphate is an antimalarial medicine that has been on the market for many years, and it also has a promising broad- spectrum antiviral effect $[72,73]$. It can boost the $\mathrm{pH}$ of lysosomes to block virus fusion with the cell membrane and then prevent virus passage and infection [39]. Some researchers have detected that the spike glycoprotein on the virus envelope connects to the ACE2 receptor to mediate SARS-CoV-2 infection $[74,75]$. Chloroquine phosphate has been announced to intervene with the glycosylation of the ACE2 receptor, thereby preventing the attaching of SARS-CoV to cells and attaining therapeutic goals [76]. Thus, chloroquine phosphate is utilized to heal COVID-19, and in vitro assays exhibit that chloroquine phosphate does hinder SARSCoV-2 and that its EC50 is $1.13 \mu \mathrm{M}$ [54]. Chloroquine phosphate is utilized for the healing of COVID-19 in adults aged 18-65 years. The patients who weigh more than $50 \mathrm{~kg}$ will take $500 \mathrm{mg}$ two times in a day for 7 days, while the patients who weigh less than $50 \mathrm{~kg}$ will receive $500 \mathrm{mg}$ two times in a day on the first and second days of treatment, and $500 \mathrm{mg}$ once daily on days 3-7 [16,10]. Chloroquine sulfate and phosphate salts were both sold as antimalarial medicine. Hydroxychloroquine has been extensively used as an antimalarial and in autoimmune ailments, such as lupus and rheumatoid arthritis (RA). These are medicines with a good safety profile with mild and transient side effects, if accurately dosed. In case of overdose or extended treatments, they can bring about cardiomyopathies and QT prolongation [77]. Chloroquine has been used in miscellaneous chronic viral diseases too. In HIV infection, no positive reactions emerged, so the drug was not contained in the recommended panel for the treatment of HIV [78]. The only viral infection in which hydroxychloroquine showed any potency was found in chronic hepatitis $\mathrm{C}$, especially if related with interferon pegylated plus ribavirin $[57,79]$. The molecular mechanism of Chloroquine against SARS-CoV is notorious $[80,81]$. Very currently, Wang, et al. [82] reported time-of- addition assay that clarified the function of CQ (EC50 1/4 1.13mM; CC50 > 100mM; SI > 88.50) at both entry along with at post-entry stages of the novel corona virus infection in Vero E6 cells [83].

In a new publication, [84] it was explained that 'according to the news update', outcomes from more than 100 cases have displayed that chloroquine phosphate is superior to the regulate healing in curbing the exacerbation of pneumonia, developing lung imaging data, boosting a virus negative adaptation, and shortening the ailment course'. Notwithstanding, no data from these clinical trials have yet been dropped to support this report, making it impractical to draw solid conclusions [85].

\section{h. Hydroxychloroquine}

As a derivative of chloroquine, hydroxychloroquine has akin potency and few side effects. Stand on its typical features of immunomodulation, antithrombotic action, and augmented inflammation, hydroxychloroquine has been practiced in the clinical cure of systemic lupus erythematosus [86]. Hydroxychloroquine has been presented to have anti-SARS-CoV activity in vitro [87], and it is clinically harmless than chloroquine [88,89]. Some clinical researchers have discovered that after healing with hydroxychloroquine, the viral load actually diminishes or even disappears, and azithromycin can improve the antiviral impact [10,90,91]. In France, 26 COVID-19 sufferers were cured for 6 days with hydroxychloroquine (200mg, three times Per day) [90]. Six of these victims also took azithromycin. Sixteen patients were served as the control group. SARS-CoV-2 RNA was checked in nasopharyngeal swabs daily concurrently with the treatment. During the trial, six patients from the cured group had to be removed and were not regarded in data analysis. Three sufferers had to be moved to intensive care units, one departed from the 
hospital on account of the patient tested negative, one broke cure beceuse of the side responses and one individual died pending the treatment. The authors announced clearance in SARS-CoV-2 RNA in the nasopharyngeal swabs in $57 \%$ of chloroquine-cured sufferers correlated to $12.5 \%$ of uncured sufferers at day 6 post-inclusion in the trial. Furthermore, a synergistic action of azithromycin and hydroxychloroquine was adviced, because all sufferers healed with this mixture eliminated viral RNA by day 6 post-inclusion. Nevertheles, as not all cases entered the research at the same stage of the ailment, it is hard to evaluate whether the clearance in viral RNA was due to the cure or due to the immune system of the patient. Besides, the mixture of chloroquine and azithromycin is related with fierce QT prolongation and should so be considered with carefulness. Before chloroquine can be believed safe and powerful as a medication for COVID-19, more researches are required [85].

\section{i. Ivermectin}

Ivermectin has been investigated onwards 1946 against avid diphtheria. It was regarded as an mysterious multifaceted 'wonder' compound in 2017 [92]. More currently it has also been applied (as already accepted by the FDA) as an anti-parasitic against scabies and evenly against HIV, Zika, Dengue, West Nile, and Influenza viruses [93]. Its mechanism of action draws in the dissociation of the preformed IMP $\alpha / \beta 1$ heterodimer, in charge for the nuclear transport of loads of viral proteins [94]. Newly, an in vivo research has shown Ivermectin's ability to decrease viral RNA up to 5000 times after $48 \mathrm{~h}$ of SARS-CoV-2 infection [95]. It is recently under trial in COVID-19 positive victims, with a dosage of $12 \mathrm{mg}$ weekly, together with hydroxychloroquine. With a familiar safety figure for pesticide use, more researches will be needed to characterize and to set up the proper dosage of Ivermectin in the healing of COVID-19 [28].

\section{j. IL-6 Inhibitors}

Tocilizumab (Actemra) is a humanised interleukin-6 (IL6) receptor antagonist that was accepted to cure victims with rheumatoid arthritis. A non-peer reviewed publication explains the outcomes of a single-arm Chinese trial in which 21 serious or critical COVID-19 sufferers got tocilizumab. Day after taking tocilizumab, the body temperature of all victims back to normal situations and continued balanced for the next days. Besides, the requirement for supplemental oxygen reduced in $75 \%$ of the cured patients. Even supposing promising, the absence of a control group makes it complex to comprehend the real advantage of this medication. Stand on these outcomes, China renewed its healing guidelines and accepted the use of tocilizumab to heal COVID-19 sufferers with severe lung damage and high IL-6 levels [85]. Tocilizumab is also investigated in administration blended with Favipinavir, to analyze a feasible synergistic effect of the two medicines. The results of this research are awaited to be assessible by the end of May/June 2020 . Tocilizumab can cause an raised risk of infections, exceptionally of the upper airways, escalated AST transaminases, hypertension, hematological effects, hepatotoxicity, gastrointestinal perforation, hypersensitivity responds to the active bacis [28,96,97]. Tocilizumab can hold up two fundamental inflammatory aspects, IL-6 and granulocyte-macrophage colony-stimulating factor, by that lowering the level of inflammation.

A multicenter RCT to appraise the efficacy and safety of tocilizumab in the medication of moderate patients at high risk of evolution toward serious and critical disorder (registration number: ChiCTR2000029765) was recently finished. Results of this trial are not yet accessible; however, they are inferred to be positive in patients with elevated IL-6 levels [57]. Sarilumab, another IL-6 receptor antagonist, practiced for rheumatoid arthritis, is being controlled in an adjusting phase- $2 / 3$ randomized, double-blind, placebo-controlled research in hospitalized severe COVID-19 victims [28]. Sarilumab is a wholly human monoclonal IgG1 antibody targeting soluble and membrane IL-6 receptors, impeding IL-6-mediated signal transduction interceded by these receptors [98] biologic is accepted as subcutaneous cure in patients over 18 years of age with moderate-to-severe active RA refractory or intolerant to one or more disease-altering antirheumatic drugs [99]. Sarilumab is recently being applied in the healing of victims with dangerous forms of COVID-19. Five RCTs are ongoing (ClinicalTrials.gov Identifier: NCT04315298, NCT04327388, NCT04324073, NCT04322773, and NCT04321993), the outcomes of which will be of great importance [57]

\section{k. Boceprevir}

Ma et. al. using the FRET-grounded enzymatic assay, assorted inhibitors containing boceprevir, GC-376, and calpain inhibitors II, and XII were identified to have effective activity with singledigit to submicromolar IC50 values in the enzymatic analysis. The mechanism of action of the hits was additional characterized using enzyme kinetic researches, thermal shift binding assays, and native mass spectrometry. Substantially, four compounds (boceprevir, GC-376, calpain inhibitors II and XII) inhibit SARS-CoV-2 viral duplication in cell culture with EC50 values varying from 0.49 to $3.37 \mu \mathrm{M}[100]$.

\section{l. Azitromycin}

Researchers suggest valuable impacts of azithromycin in decreasing viral load of hospitalized sufferers, likely intervening with ligand/CD147 receptor interactions; nonetheless, its possible impact on SARS-CoV-2 infiltration has not yet been appraised. Besides the possible action in infestation, azithromycin lessens the expression of some metalloproteinases (downstream to CD147), promotes anti-viral reactions in basic human bronchial epithelial infected with rhinovirus, diminishing viral replication and delivery. Moreover, resident lung progenitor/stem are broadly make a distinction into myofibroblasts all along pulmonary fibrosis, a complication detected in COVID-19 victims. This process, and the attainable direct viral infestation of progenitor/stem cells via 
CD147 or ACE2, could result in the lessening of these cellular stocks and defect lung repair [101].

\section{m. Baricitinib}

Baricitinib intracellularly prevents the proinflammatory indication of assorted cytokines by suppressing Janus kinase (JAK) JAK1/JAK2. It has been shown clinical advantage for the sufferers with rheumatoid arthritis (RA), active systemic lupus erythematosus and atopic dermatitis with good efficiency and safety reports. Baricitinib is awaited to cut off the transition and intracellular congregation of SARS-CoV-2 into the target cells mediated by ACE2 receptor, and heal cytokine storm boosted by COVID-19. Baricitinib has not been accepted for cytokine storm caused by SARS-CoV-2 Nevertheless, As of April 29, 2020, 14 clinical assays of baricitinib in the cure of COVID-19 have been revealed for reference, and one of which has been accomplished with promising results. In these clinical trials, participants were applied baricitinib $2 \mathrm{mg}$ or $4 \mathrm{mg}$ in a day as monotherapy or in blended with antiviral medicines (such as Lopinavir/Ritonavir) for 7-14 days. Baricitinib is recommended for mean to serious COVID- 19 patients. However based on drug commands of the US FDA, the following side responses require to be noted.

1) Severe Infections The most generally known serious infections presented with baricitinib included pneumonia, herpes zoster, and urinary tract infection.

2) Malignancy Clinical drug administration research has displayed that malignancies rule out non-melanoma skin cancers were reported in 2 victims treated with baricitinib 2 $\mathrm{mg}$ and 6 sufferers cured with baricitinib $4 \mathrm{mg}$ during the 0 to 52 week healing period.

3) Thrombosis, containing deep venous thrombosis (DVT) and pulmonary embolism (PE) has been observed at an elevated incidence in cases treated with baricitinib.

4) abnormalities like neutropenia, lymphopenia, anemia, thrombocytosis, liver enzyme rises (ALT, AST), lipid increasings (total cholesterol, LDL, HDL) and elevation of creatine phosphokinase (CK).

Therefore stay away from the use of baricitinib in victims with active, severe infection and active TB.

1) Baricitinib is not advised in sufferers with ALC (Absolute lymphocyte count) $<0.5 \times 109 / \mathrm{L}, \mathrm{ANC}<1.0 \times 109 / \mathrm{L}$ or $\mathrm{Hb}<8$ g/dL.

2) Prompt research of the cause of liver enzyme increasing is recommended. If elevates in ALT or AST are detected and drugpromoted liver injury is distrusted, interrupt baricitinib just before this diagnosis is removed.

3) Baricitinib should be utilized with caution in sufferers who have risk factors like older age, obesity, history of DVT (deep venous thrombosis)/PE(pulmonary embolism), and the utilization of selective COX-2 inhibitor [102].

\section{In silico studies: The potential drug candidates to cure COVID-19}

In this work, Borkotoky and Banerjee et. all. have used docking and simulation methods to determine tiny compound inhibitors of SARS- CoV-2 Membrane (M) and Envelope (E) proteins, which are vital for virus congregation and growing. A sum of 70 molecules from an Indian medicinal plant source (Azadirachta indica or Neem) were practically scanned against these two proteins and advanced examined with molecular dynamics simulations, which lead to the determination of a few familiar molecules with powerful connecting to both structural proteins. The molecules attach to biologically critical areas of $\mathrm{M}$ and $\mathrm{E}$, displaying their capacity to prevent the functionality of these compounds [103]. These compounds, derived from Neem, showed stable binding and interactions with critical regions of $\mathrm{E}$ and $\mathrm{M}$ needed assembly; and were predicted to have good pharmacokinetic characteristics. Nimbolin A exhibited the strongest binding free energy with both $\mathrm{E}$ and $\mathrm{M}$ proteins. Other compounds: Nimocin and Cycloartanols (24- Methylenecycloartanol and 24-Methylenecycloartan-3-one) were also prevalent ligands, binding powerfully to both proteins. A recent study has displayed ameliorating action of Neem extract on propagation and pathophysiology of another representative of the coronavirus family [104], augment the potential of these compounds as potential therapeutic preferences.

The main protease of SARS-CoV-2 is one of the significant aims to create and improve antiviral medicines. In this study, Islam et. all. have picked 40 antiviral phytochemicals to learn the perfect nominees which can play as useful inhibitors against the main protease. Molecular docking is performed using Auto Dock Vina and GOLD suite to detect the binding affinities and interactions between the phytochemicals and the main protease [105].

Among the researched 40 phytochemicals, hypericin, cyanidin 3-glucoside, baicalin, glabridin, and a-ketoamide-11r exhibit the topmost binding affinity and powerful interactions with both or at least one of the catalytic residuum (Cys145 and His41) of the main protease. These compounds display many noncovalent interactions, being hydrogen bonding, hydrophobic, and electrostatic interactions. MD outcomes show that in the physiological environment, baicalin, cyanidin 3-glucoside, and a-ketoamide-11r are the most durable ligands and they are making a higher number of interactions through hydrogen bonds with the main protease [105]. Saikosaponin is a group of oleanane analogs presented in Chinese medicinal plants and are defined for their antiviral, anti-tumor, anti-inflammatory, anticonvulsant, antinephritis and hepatoprotective actions. Besides, they have been common to possess anti-coronaviral feature by impeding the early step of viral replication containing absorption and penetration of the virus. Hence, the Sinha and co-workers' study was attempted to evaluate 
and appraise the efectiveness of various Saikosaponins against various sets of SARS-CoV-2 binding protein via computational molecular docking simulations [106].

From the binding energy and interaction researchs, the Saikosaponins $\mathrm{U}$ and $\mathrm{V}$ displayed the perfect affinity towards both the proteins proposing them to be future investigation compound as they identify the ambition interaction with NSP15, which is at the bottom of duplication of RNA and also with 2019-nCoV spike glycoprotein which control the binding to ACE2 [106]. Saikosaponin $\mathrm{U}$ and $\mathrm{V}$ have octadecahydropicene ring with substituted oxane ring but one more additional oxane ring of Saikosaponin U afford better grip into the extensive binding pocket (residues from 319-519) of spike glycoprotein. The smaller structure of Saikosaponin V makes it terrific fit ligand into the narrow binding pocket of NSP 15. Thus they can say that Saikosaponin U and V would be the prospect research interest ligand as they show the longing interaction with NSP15, which is causing the replication of RNA and also with 2019nCov spike glycoprotein which control the linkage with ACE2 [106]. The paper have been written by Enmozhi and co-workers assesses the molecule Andrographolide from Andrographis paniculata as a possible inhibitor of the main protease of SARS-COV-2 (Mpro) through in silico studies like molecular docking, target analysis, toxicity prediction and ADME prediction. Andrographolide was docked well in the binding site of SARS-CoV-2 Mpro [107].

The compound have excellent properties of drug-ability as well tiny biomolecule. The molar refractivity of the compound proves that the drug compound is permeable through peculiar membranes and can remain stable even in the midst of strong or weak solute-solvent, solvent- solvent interactions. Through lipophilicity of the drug compound we can notice that the compound has ideal property for oral and intestinal absorption and is able to be absorbed sub-lingual as well. Through water solubility characteristics predicted the drug is free soluble [107]. In the Fakhar and co-workesrs' study, the nominee anthocyanin-derived molecules from PubChem library were filtered seeing antiviral properties of anthocyanins. The structure-based pharmacophore modeling was deepened standed on the co-crystallized structure of the enzyme with its biological effective inhibitor. The spawned hypotheses were practiced for virtual screening-based PHASE Screen Score. Delphinidin 3-sambubioside-5-glucoside [108] Delphinidin 3,3' -di-glucoside-5-(6-p-coumarylglucoside) [109] 2-(3,4,5-Trihydroxyphenyl)-3-[6-[(E)-3-(4-hydroxyphenyl) acryloyl]-beta-D-galactopyranosyloxy]-5,7-dihyd roxy-1-benzopyrylium 2-(3,4,5- Trihydroxyphenyl)-3-[6-[(Z)-3-(4-hydroxyphenyl) acryloyl]-beta-D-galactopyranosyloxy]-5,7-dihydroxy-1-benzopyrylium 3-0-[b-D-Glucopyranosyl-(1->2)-[4-hyd roxycin na moyl- $(->6)]$ - b-D - glu co pyranoside] (E-), 5-0-(6-O-malonyl-b-D-glucopyranoside) Pelargonidin3-O-[b-D-Glucopyranosyl-(1->2)-[4-hydroxycinnamoyl-(->6)]-b-D-glucopyranoside](E-) 5-0-(6-O-malonyl-b-D- glucopyranoside) [111,112] 3-< [4,5-dihydroxy-6-(hydroxymethyl)-3-[(3,4,5-trihydroxy-6-< [hydroxy(4-oxocyclohexa-2,5-dien-1-ylidene)methoxy] methyl $>$ oxan2- yl)oxy] oxan-2-yl] oxy>-2-(3,4-dihydroxyphenyl)-7-hydroxy-5-< [3,4,5-trihydroxy-6-(hydroxymethyl)oxan-2-yl]oxy>-1lambdachromen-1-ylium [111,112] Cyanidin 3-(60 '-p-coumarylsambubioside) [113] were examined.

The six outstanding top molecules using added precision docking protocol were chosen hinged on their docking binding affinities and analyzed for ADMET prediction-based physicochemical and pharmacokinetic descriptors and MD simulations analysis. MD simulations way disclosed the two greatly selective molecules i.e. 44256921(Delphinidin 3,3' -di-glucoside-5-(6-p-coumarylglucoside) [109] and 131751762(3-0-[b-D-Glucopyranosyl-(1->2)-[4-hydroxycinnamoyl-(->6)]-b-D-glucopyranoside](E-),5-0-(6-0-malonyl-b-D-glucopyranoside) Pelargonidin3-0-[b-D-Glucopyranosyl-(1->2)-[4-hydroxycinnamoyl-(->6)]-b-D-glucopyranoside](E-) 5-0-(6-0-malonyl-b-D- glucopyranoside) [111-112] possessed considerable binding affinity and likely prevention of the target. Depend on their complete findings, compounds 44256921 and 131751762 could be suggested as promising hits against SARS-CoV-2 Mpro enzyme [114]. The other current computational representation and molecular dynamics study evidently demonstrates the antiviral action [115] of Plantiricin compounds, because of multiple mechanistic approach by metabolic product of Lactobacillus plantarum prevents the entry by binding with RdRp, RBD, and ACE2. The blocking of leading structural protein $S$ is one of the essential accessory protein, acting a critical role in the life cycle of SARS-CoV-2 can verify to be one of the best target for other molecules. The allegation is substantiated by Molecular dynamics model that make more powerful stability of the complexes of plantaricin $w$ and SARS-CoV-2 RdRp enzyme, RBD of spike protein, and human ACE2 receptor [116].

The present Anwar and co-workers' research is a work for a computational point to inhibit the leftover binding protein (RBP) on spike proteins (S), Angiotensin-Converting Enzyme 2 (ACE2) receptor proteins by probiotics i.e Plantaricin BN, Plantaricin JLA9, Plantaricin W, Plantaricin D together with RNA-dependent RNA polymerase (RdRp). Docking analysis were formed for attaining the binding energies for Plantaricin metabolites. The binding energies for Plantaricin W were 14.64, 11.1 and 12.68 for polymerase, RBD and ACE2 accordingly relatively extreme with other molecules [116]. Plantaricin W, D, and JLA-9 were can inhibit the residues (THR556, ALA558) encircling the deep grove catalytic spot (VAL557) of RdRp making them more curatively active for COVID-19. Molecular dynamics analysis make more powerful stability of the complexes of plantaricin $\mathrm{w}$ and SARS-CoV-2 RdRp enzyme, RBD of spike protein, and human ACE2 receptor [116]. Buriti oil (Mauritia flexuosa L.) is a natural oil extracted from the fruit of the palm and is very familiar in the legal Amazon region, Brazil. In the Costa and associates' present investigation, the anti-Covid-19 biological 
action of some compounds of Buriti oil was scanned utilizing in silico techniques of Molecular Docking and Molecular Dynamics Simulations. The leading outcomes of Molecular Docking disclosed beneficial interaction energies in the formation of the 2GTB peptidase complex (main peptid- ase of SARS-CoV) with the 13-cisb-carotene ligands (DGbind 1/4 10.23Kcal mol1), 9-cis -b-carotene (DGbind 1/4 9.82Kcal mol1), and a-carotene (DGbind 1/4 8.34Kcal mol1) [117].

The investigation of the interactions determined in both Molecular Docking and Molecular Dynamics and, therefore, the values of energies free of desirable interactions for molecules 13-cis-b-carotene, 9-cis-b-carotene, and a-carotene against 2GTB peptidase indicate that these compounds are promising nominee for planning novel medicines to combat Covid-19 [117]. Cefuroxime also as a high-ranked possible inhibitor medicine against SARS-CoV-2 proteins. Six researches were described. These studies showed Cefuroxime as a possible inhibitor of 3 key SARS-CoV-2 proteins; main protease, RNA dependent RNA polymerase, and ACE2- Spike complex [118]. Galvez and colleagues [119] applied a Molecular Topology (MT) methodology that has been outstanding in analyzing medicine for cancer, Alzheimer's illment, and Malaria [120]. The MT way involves depicting the structure, and by extension, the pharmacologic effect of medicines or compounds by a series of numbers named topological indices. Galvez and colleagues chose Lopinavir, the HIV-1 protease that was concluded in some researches to own activity against Mpro, as a gold standard drug. Utilizing the MT method, they scanned about 15,000 compounds from 2 drug databases and determined 22 other medicines, covering Cefuroxime, that are concluded to attach stronger than Lopinavir. Lopinavir possessed an index value of 2.9 while Cefuroxime had an index value of 3.9 [118]

Almeciga-Diaz and colleagues [121] utilized a proprietary algorithm [122] to evaluate a subgroup of ZINC database for medicine that could connect to the active hole of Mpro. They detected a greatly strong correlation (R2 1/4 0.89) between the binding energy and noted IC50 of these inhibitors. Thereupon, they anticipated IC50 stand on binding energy. From scanning of over 11,000 medicines, they found 10 possible inhibitor medicines, containing Cefuroxime, that owned smaller binding energy than the formerly mentioned inhibitors. Cefuroxime listed 8th and was concluded to attach with affinity energy of $-9.2 \mathrm{kcal} / \mathrm{mol}$ with an IC50 of 2.09mM [118]. Koulgi and co-workers [123] applying both a "direct docking" and an "ensemble docking" approach. The direct docking was a simple docking of promising medicines against the crystal structure of Mpro while the altogether coming included docking against variations in conformation of the active pocket of Mpro, which generally cause to perfect outcomes. Cefuroxime, via trade name of Ceftin, was classified as the second-successful medicine from the FDA drug library via the whole method with a grid score of -49.33 [118]. Al-Khafaji and associates [124] practiced covalent docking scanning to determine potent compounds that could connect covalently, thus irreversibly, to Cys145 of the active point of Mpro. Cys145 of Mpro has been found as an important residue that can be covalently attached by compounds to impede function of Mpro [125-127]. They confirmed that the top 8 compounds showed a greater affinity to form covalent, irreversible bond with Cys145 of the active cavity of Mpro. Cefuroxime was the $5^{\text {th }}$ apical ranking medicine with a binding energy of $-54.25 \mathrm{kcal} /$ mol while Remdesivir rated third with a binding energy of -65.19 $\mathrm{kcal} / \mathrm{mol}$ [118]. Wu et. al [128] screened FDA-accepted drugs from ZINC library, and a library of recognized antiviral agents against active points all SARS-CoV-2 proteins. The binding energies of encouraging medicine candidates were articulated as ICM scores and ICM mfscores (mean force scores). The ICM score is a measure of the total experimental function of the concluded physical interaction while the ICM mfscore is an separate score of the power of drug-receptor interaction [129-131]. Per the ICM user guide, the score is regarded as perfect scoring to handle for docking result researches, and ICM scores less than -32 are mainly regarded to be acceptable scores [129]. Wu and co-workers analysed medicine nominees with ICM scores less than -30 or ICM mfscores less than -110 to have possible activity against marked proteins of SARS$\mathrm{CoV}-2$. From the ICM score input afforded in auxiliary files, against Rdrp, Cefuroxime had an ICM score of -41.30 , which was the topmost, and mfscore of -63.04. Remdesivir owned a score of -27.4 and a mfscore of -113 [118].

Elfiky [132] also presented possible binding of Cefuroxime to RdRp. The author performed MDS with molecular docking to the binding of a few of pre-chosen medicines involving antiviral agents and Cefuroxime to RdRp. The median binding energy for Cefuroxime at $-6.875 \mathrm{kcal} / \mathrm{mol}$ was within the limit of error of Remdesivir at $-7.16 \mathrm{kcal} / \mathrm{mol}$ [118]. Dar'ya and colleagues [133] concluded that Cefuroxime may prohibit the ACE2-Spike complex. Once, they developed a system named PolypharmDB that included the estimated binding profiles of over 10,000 confirmed and experimental medicines. PolypharmDB was then questioned for possible medicines that could prevent SARS-CoV-2 proteins of interest, which uncovered Cefuroxime as a hit 5 medicines that may impede ACE2-Spike protein complex [118]. According to the paper written by Breithaupt-Faloppa et. all., the studies displayed that the viral infection promotes a vascular mechanism in the lung, which involved vasodilation and endothelial malfunction. Besides, the ratio of CD4+ T and CD8+ T lymphocytes were powerfully cut down in sufferers with serious SARS-CoV-2 infection. Estradiol is attached with CD4+ T cell numbers and raises T-reg cell populations, altering immune reactions to infection. It is known that estradiol uses a careful action on endothelial function, stimulating the forming of nitric oxide (NO) via endothelial nitric oxide synthase.

Estrogen weakens the vasoconstrictor reaction to different stimuli and promotes vasodilation in the pulmonary vasculature along stress cases like hypoxia. It uses a type of quick reactions, which are started after its coupling with membrane receptors, 
which in turn, may absolutely regulate vascular reactions in pulmonary illness and aid to keep up microvascular flow. Direct and indirect mechanisms controlling the actions of estradiol were searched, and the outcomes show an attainable defensive effect of estradiol against COVID-19, pinpointing that it may be regarded as an adjuvant healing compound for the cure of patients influenced by the novel coronavirus [134]. Da Silva and research group have carried out a molecular docking analysis running 171 essential oil compounds with SARS-CoV-2 main protease (SARS-CoV-2 Mpro), SARS-CoV-2 endoribonuclease (SARS-CoV-2 Nsp15/NendoU), SARS-CoV-2 ADP-ribose-1"-phosphatase (SARS-CoV-2 ADRP), SARS-CoV-2 RNA-dependent RNA polymerase (SARS-CoV-2 RdRp), the binding site of the SARS-CoV-2 spike protein (SARS-CoV-2 rS), and human angiotensin-converting enzyme (hACE2). The molecule with the perfect normalized docking result to SARS-CoV-2 Mpro was the sesquiterpene hydrocarbon (E)- $\beta$-farnesene. The perfect docking ligands for SARS-CoV Nsp15/NendoU were (E,E)$\alpha$-farnesene, (E)- $\beta$-farnesene, and (E,E)-farnesol. (E,E)-Farnesol exhibit the most exothermic docking to SARS-CoV-2 ADRP. Sadly, the docking energies of (E,E)- $\alpha$-farnesene, (E)- $\beta$-farnesene, and (E,E)-farnesol with SARS-CoV-2 points were in comparison feeble compared to docking energies with other proteins and are, thus, improbable to interact with the virus points. Nonetheless, essential oil compounds may behave synergistically, essential oils may potentiate other antiviral drugs, or they may bring some comfort of COVID-19 symptoms [135].

Ding et. al. have reported DG (Diammonium glycyrrhizinate), a marketed Chinese traditional drug with a steroid-like action, in mixed with VC (Vitamin C) as a probable anti- inflammatory healing to relieve intense signs from COVID-19. DG is the effective compound in the traditional Chinese pharmaceutic herb licorice. It is biotransformed into glycyrrhetinic acid, which has a chemical structure akin to that of corticosteroid and therefore functions as a glucocorticoid-resembling medicine, which may serve afford immune adjustment versus cytokine storm and lessen inflammation, even though might be barely stringent than steroids [136]. It has been indicated glycyrrhizic acid analogs possess antiviral action con SARS-CoV infection in Vero cells [137]. Their article here reveals a case of nonhospital COVID-19 that displayed originally positive reactions to DG healing. Although the literal functions of DG versus SARS-CoV-2 infection and the related immunopathology count on additional analysis, it is attainable that the curative actions of DG detected in this intense COVID-19 sufferer were a combinatory outcome of the antiviral and anti- inflammatory actions of DG in the respiratory and neurological systems. Given these promising pharmacological actions and the proved safety, also the cheap and extensive availability of DG and VC, they recommend that a combination of these might be a valuable nominee for possible medication to aid ease the serious symptoms of COVID-19 along self-quarantine [138,139].
Sinha and colleguages' current investigation was performed to label the active compound from the liquorice con various protein targets of COVID-19 utilizing an in-silico method. The molecular docking demonstration analysis of 20 molecules together with two standard antiviral medicines (Lopinavir and Rivabirin) was performed with the aid of Autodock vina software utilizing two protein targets from COVID-19 i.e. spike glycoprotein (PDB ID: 6VSB) and Non-structural Protein-15 (Nsp15) endoribonuclease (PDB ID: 6W01). From the detected binding energy and the binding interactions, glyasperin A exhibited great affinity against Nsp15 endoribonuclease with uridine particularity, while glycyrrhizic acid was discovered to be perfect fitted for the binding spot of spike glycoprotein and further, prohibited the inlet of the virus into the host cell [140]. The binding free energy of both glyasperin A and glycyrrhizic acid was measured from the complete MD simulation trajectory through the MM-PBSA method and discovered to great binding affinity facing the specific protein receptor pocket. Hence, glyasperin A and glycyrrhizic acid could be regarded as the perfect compound from liquorice, which could get beneficial against COVID-19 [140]. Nitazoxanide is a pro-drug for tizoxanide, which has wide-spectrum antiviral characteristics, has a large numbers of viral signs and exhibits hopeful pharmacodynamics against Coronaviridae [141]. It has not yet been investigated on COVID-19 sufferers but formerly displayed a low in vitro active concentration (eC50) against Middle east respiratory syndrome coronavirus and dangerous acute respiratory syndrome coronavirus [142]. Nitazoxanide was so picked out as a perfect nominee for conceivably inhibiting SARS-Cov-2. To evaluate inhibition potential, investigators correlated the maximum serum concentration of tizoxanide (Cmax) with the in vitro eC50 for nitazoxanide for SARS-Cov-2 [143]. Previous evidences of nitazoxanide vary broadly. It is certified by the US Food and Drug Administration (FDA) for giardiasis [144]. Notwithstanding, it has been examined and utilized for many other illnesses, involving cryptosporidiosis diarrhoea in HIV patients, influenza, hepatitis viruses, rotavirus and norovirus. As such, the safety description of nitazoxanide is alternatively announced and requires clarification before likely large-scale experiment and healing in the COVID-19 pandemic.

Commonly, COVID-19 cure courses are applied for 7-14 days; so, whether nitazoxanide is safe to apply requires to be confirmed for this period $[143,145]$. Nitazoxanide displays an overall agreeable safety chart, with no important dissimilarity in the existence of overall AEs (adverse effects), severe or gastrointestinal AEs correlated with other antimicrobial regimens or with placebo control. More proof is required regarding particular hepatorenal and cardiovascular effects, also the likely for teratogenicity, however existing indication provides no exact explanation for matter. Though, they advise attention and cautious screening in hepatorenal damaged patients [143]. A Mexican trial correlating nitazoxanide with hydroxychloroquine for COVID-19 is presently newcomer (US Clin- 
ical Trials registry number NCT04341493) participants. Additional clinic researches in COVID-19 cases should be started, but the great presented in vitro effect of nitazoxanide con SARS-COV-2 should also be proved. If competence versus SARS- Cov-2 is testified in clinical trials, nitazoxanide may depict a harmless and economical healing in the continuing pandemic [143]. As mentioned the review written by Yanfang and co-workers, aescin isolated from Aesculus hippocastanum and reserpine isolated from various Rauwolfia species [146], were both exhibit to have significant anti-SARS actions with the concentration for $50 \%$ of maximal effect (EC50) values of 3.4 and $6.0 \mathrm{mmol} / \mathrm{L}$, accordingly [147].

Ginsenoside-Rb1, one of the pharmacologically active components of Panax ginseng [148], was presented to have activity against SARS-CoV at the concentration of $100 \mathrm{mmol} / \mathrm{L}$ [147]. Boenninghausenia sessilicarpa (Rutaceae), a slender and perennial plant, has long been accepted as a coumarin- rich Chinese herbal drug dispensed in the temperate hilly regions at an altitude of $1500-2500 \mathrm{~m}$ in southwestern China. It is traditionally utilized for the cure of fever, festers and tonsillitis. Leptodactylone, isolated from B. sessilicarpa, was discovered to possess a powerful protective action con virus-infected cells and anti- SARS-CoV action with the inhibition rate of $60 \%$ at $100 \mathrm{mg} / \mathrm{ml}$ [149]. As well as, it has been displayed that lycorine obtained from Lycoris radiata was determined to own anti-SARS-CoV action with EC50 value of $15.71 .2 \mathrm{nmol} / \mathrm{L}$ [150]. Latest research of repurposing of clinically accepted medications for treatment of COVID-19 showed that cepharanthine, a bisbenzylisoquinoline alkaloid from tubers of Stephania japonica (Qianjinteng), exhibited a effective inhibition of a 2019-nCoV-related pangolin coronavirus GX_P2V infection, with EC50 value of $0.98 \mathrm{mmol} / \mathrm{L}$ using a 2019-novel coronavirusassociated coronavirus model [151,152]. Kumar et. al. have searched the binding possibility of Withaferin-A (Wi-A), Withanone (Wi-N) and caffeic acid phenethyl ester to TPMRSS2 in contrasting to its common inhibitor, Camostat mesylate. They discovered that both Wi-A and Wi-N could connect and tightly interact at the catalytic pocket of TMPRSS2. Wi-N displayed powerful interactions with TMPRSS2 catalytic residues than Wi-A and was able to bring about alterations in its allosteric cavity too. Moreover, they searched the impact of Wi-N on TMPRSS2 expression in MCF7 cells and discovered significant downregulation of TMPRSS2 mRNA in cured cells concluding dual effect of Wi-N to prevent SARS-CoV-2 entry into the host cells. As the natural molecules are simply assessible/ cheap, they may present a tprompt curative/preventive advantage for the handling of SARS-CoV-2 pandemic indeed.

They also notify that Wi-A/Wi-N composition differentiates in various parts of Ashwagandha and guarantees attentive regard for their application [153]. Kumar and colleagues have tested the binding ability of Withaferin-A (Wi-A), Withanone (Wi-N) (active with anolides of Ashwagandha) and Caffeic Acid Phenethyl Ester (CAPE, bioactive component of propolis) to a deeply preserve protein, Mpro of SARS-CoV-2. They detected that Wi-N and CAPE, though not Wi-A, connect to the substrate-binding region of SARSCoV-2 Mpro with virtue and binding energies equal to an previously declared N3 protease inhibitor. Identical to N3 inhibitor, Wi-N and CAPE were interacting with the immensely preserved residues of the proteases of coronaviruses. The binding strength of these compounds was farther analyzed running molecular dynamics demonstrations. The binding free energies measured utilizing MM/GBSA for N3 inhibitor, CAPE and Wi-N were comparable too. Data displayed here concluded that these natural molecules may possess the possible to impede the functional action of SARS-CoV-2 protease (an essential protein for virus survival), and thus

(i) May associate to gain time and cost needed for creating/ improvement, and primary scanning for anti-COVID medicins,

(ii) May suggest some healing benefit for the handling of new fatal corona- virus,

(iii) Warrants preferenced additonal verification in the laboratory and clinical assays [154].

In accordance with Straughn et. al., two separate research groups have found that Withaferin A (WFA), a steroidal lactone with anti-inflammatory and anti-tumorigenic characteristics, may bind to the viral spike (S-) protein of SARS-CoV-2.

Also, initial data from Straughn's research group has presented that WFA does not alter expression of ACE2 in the lungs of tumorincluding female mice. Downregulation of ACE2 has currently been demonstrated to boost the severity of COVID-19. Thus, WFA exhibits real potential as a therapeutic agent to cure or prevent the spread of COVID-19 due to the noted interference in viral S-protein to host receptor binding and its lack of effect on ACE2 expression in the lungs [155]. According to Tripathi and co-workers' publication, the traditional medical specialists extensively apply Indian medicinal herb Withania somnifera (Ashwagandha) natural components, named withanolides for healing various infections. The main protease (Mpro) of SARS-CoV-2 acts a critical role in illment propagation by handling the polyproteins which are needed for its duplication. Therefore, it stands for a significant target for medicine discovery. In the present research, they assess the probable of 40 natural chemical compounds of Ashwagandha to analyze a potential inhibitor versus main protease of SARS-CoV-2 by selecting the computational technique. The docking research disclosed that four compounds of Ashwagandha; Withanoside II $(-11.30 \mathrm{Kcal} / \mathrm{mol})$, Withanoside IV (-11.02 Kcal/mol), Withanoside V (-8.96Kcal $/ \mathrm{mol})$ and Sitoindoside IX $(-8.37 \mathrm{Kcal} / \mathrm{mol})$ displayed the extreme docking energy in a group of the picked natural compounds [156].

Moreover, MD demonstration research of 100ns calls Withanoside $\mathrm{V}$ have powerful binding affinity and hydrogenbonding interactions with the protein active cavity and shows its stability in the active cavity. The binding free energy value compares with the top value of $87.01 \pm 5.01 \mathrm{Kcal} / \mathrm{mol}$ too as correlated to other chosen compounds. Finally, Tripathi and co-workers' study 
proposes that Withanoside $\mathrm{V}$ in Ashwagandha may be serve as a possible inhibitor con Mpro of SARS-CoV-2 to fight COVID-19 and may own an antiviral activity on nCoV [156]. In the Chikhale et. al.'s manuscript, molecular docking investigations offered Withanoside $\mathrm{X}$ and Quercetin glucoside from W. somnifera possess desirable interactions at the binding site of chosen proteins, that is, 6W01 and 6M0J. The topmost phytochemicals from docking analyses, submitted to 100ns molecular dynamics (MD) offered Withanoside $\mathrm{X}$ with the greatest binding free energy (DGbind 1/4 89.42kcal/ $\mathrm{mol}$ ) as the most encouraging inhibitor. Along MD analyses, the compound adjusts its conformation for perfect fitting with the receptor active pocket confirming the powerful binding affinity.

Placed on confirmed therapeutic, that is, immunomodulatory, anti- oxidant and anti-inflammatory functions and logical possible versus $n-\mathrm{CoV}-2$ proteins, Indian ginseng could be one of the opportunity as an antiviral agent in the healing of COVID 19 [157]. Kar and collegues' present investigation used an in silico method to evaluate the inhibitory action of the phytochemicals got from GC-MS analysis of twelve Clerodendrum species versus the essential spike protein, main protease enzyme Mpro and RNAdependent RNA polymerase (RdRp) of SARS-CoV-2. An large-scale molecular docking research of the phytocompounds at the active binding cites of the viral proteins disclosed hopeful inhibitory effect of the phytochemicals taraxerol, friedelin and stigmasterol. Molecular mechanics-generalized Born surface area (MM-GBSA) binding free energy appraisal affirmed that taraxerol was the most encouraging nominee showing the extreme binding potency with all the involved with SARS-CoV-2 proteins associated in the present analysis. Their observations were verified by robust molecular dynamics demonstrations of the complexes of the viral proteins with taraxerol for a timescale of 40 nanoseconds. It was compelling to mention that taraxerol displayed exceptional binding energy values with the related viral proteins than the medicins that are pointedly targeted con them.

The actual outcomes assure to afford new avenues to advanced assessment the potential of the phytocompound taraxerol in vitro and in vivo towards its profitable formation as a SARS-CoV-2 inhibitor and fight the disastrous COVID-19 [158]. Chikhale et. al.s' current investigation was engage in scan and determine the possible leads from the Indian Ayurvedic plant, Asparagus racemosus (Willd.) versus SARS-CoV-2 performing molecular docking and dynamics analyses. The docking studies was utilized on the Glide module of Schro€dinger suite on two various proteins from SARSCoV-2 viz. NSP15 Endoribonuclease and spike receptor-binding domain. Asparoside-C, Asparoside-D and Asparoside -F were detected to be most powerful con both the proteins as affirmed through their docking result and affinity. MM-GBSA based binding free energy calculations as well as provide the most affirmative binding affinities of Asparoside- $\mathrm{C}$ and Asparoside-F with binding energies of 62.61 and $55.19 \mathrm{Kcal} / \mathrm{mol}$ subsequently with spike receptor-binding domain and NSP15 Endoribonuclease [159]. In the current study of Naidoo and co-workers, the endeavour was assessing the inhibitory possibility of cyanobacterial metabolites at the active binding cites of the two important SARS-CoV-2 proteases i.e main protease (Mpro) and the papain-like protease (PLpro) that proteolytically transforms viral polyproteins and aid viral replication, using an in silico molecular interaction-standed approach.

It was clear from their research stand on the binding energy values that the compounds cylindrospermopsin, deoxycylindrospermopsin, carrageenan, cryptophycin 52, eucapsitrione, tjipanazole, tolyporphin and apratoxin A displayed promising inhibitory capacity versus the SARS-CoV-2 M pro. The metabolites cryptophycin 1, cryptophycin 52 and deoxycylindrospermopsin were noted to show promising binding energy data with the PLpro of SARS-CoV-2. Following evaluation of physicochemical characteristics and likely toxicity of the compounds tracked by robust molecular dynamics demonstrations and analysis of MM-PBSA energy recording function demonstrated deoxycylindrospermopsin as the most hopeful inhibitory nominee con both SARS-CoV-2 proteases. Present investigation data give broad opportunity to additional achievement the ability of deoxycylindrospermopsin as a favorable inhibitor of SARS-CoV-2 in vitro and in vivo and concreate the base for the improvement of new active therapeutics versus COVID-19 [160]. The main protease (Mpro) of SARS CoV-2, an essential element of this viral replication, is regarded as a main target for anti-COVID-19 medicine improvement. In order to detect possible Mpro inhibitors, Ghosh and research group have picked eight polyphenols from green tea, since these are previously acknowledged to display antiviral activity con many RNA viruses.

They have illuminated the binding affinities and binding modes among these polyphenols containing a familiar Mpro inhibitor N3 (possessing binding affinity $7.0 \mathrm{kcal} / \mathrm{mol}$ ) and Mpro utilizing molecular docking investigations. Whole eight polyphenols show perfect binding affinity versus Mpro (7.1 to $9.0 \mathrm{kcal} / \mathrm{mol}$ ). Nevertheless, just three polyphenols (epigallocatechin gallate, epicatechingallate and gallocatechin-3-gallate) react powerfully with one or both catalytic residues (His41 and Cys145) of Mpro. Pharmacokinetic examination revealed that these polyphenols own desirable drug-resemblance properties too. Altogether, their study exhibits that these three polyphenols can be exploit as promising inhibitors versus SARS CoV-2 Mpro and are encouraging medicine nominees for COVID-19 cure [161]. Some flavonoids are familiar to inhibit 3CLpro from SARS-CoV which brings about SARS. Since their sequence identity is $96 \%$, a analogous way was performed with a flavonoid library. Baicalin, herbacetin, and pectolinarin have been found to block the proteolytic action of SARS-CoV-2 3CLpro. An in silico docking research showed that the binding conditions of herbacetin and pectolinarin are akin to those obtained from 
the catalytic domain of SARS-CoV 3CLpro. However, their binding affinities are dissimilar due to the application of whole SARSCoV-2 3CLpro in Jo et. al.s' study. Baicalin displayed an influential inhibitory activity against SARS-CoV- 2 3CLpro and its docking mode is unlike from those of herbacetin and pectolinarin. This research offers significant scaffolds to design 3CLpro inhibitors to improve antiviral agents or health-foods and dietary supplements to cope with SARS-CoV-2 [162].

In order to determine probable useful compounds versus the Mpro for clinical application, Bhardwaj and collegues docked a group of 65 bioactive compounds of Tea plant pursueded by analysis of the wide conformational space of protein-ligand complexes by long term molecular dynamics (MD) simulations $(1.50 \mathrm{~ms})$. Best three bioactive metabolites (Oolonghomobisflavan-A, Theasinensin-D, and Theaflavin-3-0-gallate) were chosen by correlating their docking data with repurposed medicine (Atazanavir, Darunavir, and Lopinavir) con SARS-CoV-2. Oolonghomobisflavan-A molecule exhibited a adequate number of hydrogen bonds with Mpro and greatest MM-PBSA binding energy when matched to all three proper drug molecules along the time of demonstration. Bhardwaj and co-workers' study displayed Oolonghomobisflavan-A as a possible bioactive metabolite to act as an inhibitor for the Mpro of SARS-CoV-2 [163]. In the Kumar and research groups' current study, they declare new natural metabolites specially, ursolic acid, carvacrol and oleanolic acid as the promising inhibitors against pro main protease (M) of COVID-19 by performing integrated molecular modeling programs. From a combination of molecular docking and molecular dynamic (MD) simulations, they discovered three ligands connect to protease during $50 \mathrm{~ns}$ of MD demonstrations.

Moreover, the molecular mechanic/generalized/ Born/ Poisson-Boltzmann surface area (MM/G/P/BSA) free energy measurements displayed that these chemical compounds own stable and desirable energies generating powerful attaching with binding site of Mpro protein. Entire these three compounds, i.e. ursolic acid, carvacrol and oleanolic acid, have been subjected to the ADME (Absorption, Distribution, Metabolism, and Excretion) feature as well as Lipinski's rule of five. The research provides a fundamental base and indicates that the three phytochemicals, viz. ursolic acid, carvacrol and oleanolic acid could exploit as potential inhibitors in adjusting the Mpro protein's function and managing viral duplication [164]. It was just published that Broussonetia papyrifera polyphenols successfully prevent the catalytic action of SARS CoV-1 and MERS Mpro. However whether these polyphenols show any inhibitory impact on SARS CoV-2 Mpro is far from clear. To understand this situation, here Ghosh et. al.s' have selected computational approaches. Polyphenols having proper drug-resemblence properties and two reused medicins (lopinavir and darunavir; owing binding affinity 7.3 to $7.4 \mathrm{kcal} /$ mol) were docked versus SARS CoV-2 Mpro to investigate their binding characteristics. Just six polyphenols (broussochalcone A, papyriflavonol A, 3'-(3-methylbut-2-enyl)-3',4',7-trihy- droxyflavane, broussoflavan A, kazinol F and kazinol J) had interplay with both the catalytic residues (His41 and Cys145) of Mpro and displayed favorable binding affinity (7.6 to $8.2 \mathrm{kcal} / \mathrm{mol}$ ). Molecular dynamic demonstrations (100ns) disclosed that whole Mpro-polyphenol complexes are more balanced, conformationally less fluctuated; somewhat less compact and slightly expanded than Mpro-darunavir/lopinavir complex. Indeed the number of intermolecular H-bond and MM-GBSA investigations displayed that these six polyphenols are more powerful Mpro inhibitors than the two reused drugs (lopinavir and darunavir) and may act as hopeful anti-COVID-19 drugs [165].

Sharma et. al. s' studies have determined six probable inhibitors of Mpro enzyme, out of which four are commercially assessible FDA accepted medicines (Cobicistat, Iopromide, Cangrelor, and Fortovase) and two are from Specs library of natural metabolites (Hopeaphenol and Cyclosieversiodide-A). While Cobicistat and Fortovase are familiar as HIV medicine, Iopromide is a inverse agent and Cangrelor is an anti-platelet medicin. Moreover, molecular dynamic (MD) demonstrations utilazing GROMACS were carried out to measure the stability of the topmost metabolites in the active pocket of Mpro. Afterwards, large-scale computational research, they suggest that Cobicistat and Hopeaphenol display ability to be superior medicines that can set up the ground of healing COVID-19 disease [166]. Das and research groups' in silico (Virtual molecular docking and Molecular dynamics simulation) studies pointed out that flavonoid type phytochemicals of calendula (rutin, isorhamnetin-3-0-b-D, calendoflaside) may be greatly effective for inhibiting Mpro which is the main protease for SARS-CoV-2 leading to the deadly disease COVID- 19. Rutin is already used as a medicine and the other two compounds can be made convenient for future use. Thus the research displays a way to combat COVID-19 by the utilization of major flavonoid based phytochemicals of Calendula officinals [167].

Prasanth and co-workers' research is aimed to identfy the phyto-derived antiviral molecules from Cinnamon versus COVID-19 main protease enzyme and to comprehend the in silico molecular principle of its action. In the present study, 48 isolated metabolites from Cinnamon fetched from the PubMed library, are submitted to docking research. Their investigation displays that the nine phytochemicals of Cinnamon are pretty potent con the main protease enzyme of COVID-19. Further MD demonstrations could determine Tenufolin (TEN) and Pavetannin C1 (PAV) as top compounds. Utilizing modern strategies, these phytocompounds from a natural source might form a safe medication or encourage lead determination. Determined hit molecules can be more available for in vitro and in vivo studies to analysis their potency against COVID-19 [168]. According to the paper of Chowdhury, the main protease of COVID-19 virus is Mpro or 3CLpro which is an important $\mathrm{CoV}$ enzyme and an appealing medicine target as it acts a critical role in interfering viral replication and transcription. In the current Chowdhury's study, 3CLpro is utilized to study drug:3CLpro 
interactions and hence to search whether entire or any of the major chemical components of Tinospora cordifolia (e.g. berberine (C20H18N04), b-sitosterol (C29H500), coline (C5H14NO), tetrahydropalmatine (C21H25NO4) and octacosanol (C28H580)) can be exploited as an antiviral agent versus SARS-CoV-2. The in silico research carried out utilizing appliances of network pharmacology, molecular docking involving molecular dynamics have disclosed that among all studied phytochemicals in Tinospora cordifolia, berberine can adjust 3CLpro protein's function because of its simple inhibition and hence can manage viral replication. The preference of Tinospora cordifolia was stimulated by the fact that the major compounds of it are acknowledged to be accountable for different antiviral actions and the cure of jaundice, rheumatism, diabetes, etc [169].

The objective of Abdelli et. al.'s current investigation is to concentrate on the in silico analysis to scan for another medicine that can prevent the activity of the angiotensin converting enzyme 2 (ACE2) as a receptor for SARS-CoV- 2, possible healing target of the COVID-19 virus exploiting natural metabolites (Isothymol, Thymol, Limonene, P-cymene and c-terpinene) obtained from the essential oil of the antiviral and antimicrobial herb Ammoides verticillata (Desf.) Briq. which is placed in the occidental Algeria areas. Their research discloses that Isothymol, a major compound of this herb, provides the perfect docking values, correlated to, the co-crystallized inhibitor b-D-mannose of the enzyme ACE2, to Captropil medicine as perfect ACE2 inhibitor and to Chloroquine antiviral medicine also related in other mechanisms as inhibition of ACE2 cellular receptor. In silico (ADME), drug-likeness, PASS \& P450 pocket of metabolism assuming, pharmacophore Mapper exhibited that the metabolite Isothymol has provided a best outcomes correlated to the b-D- mannose co-crystallized inhibitor, to Captopril and Chloroquine medicine. Besides the other natural metabolites provided beneficial results. The Molecular Dynamics Demonstration analysis displayed fine result for the IsotymolACE2 docked complex. This research disclosed for the first time that Isothymol is a utilitarian inhibitor of angiotensin converting enzyme 2 activity and the contents of essential oils Ammoides verticillata can be utilized as promising inhibitors to the ACE2 receptor of SARS-CoV-2 [170].

In accordance with the Ahmad and collegues' manuscript, in the light of previously published possible curative employments of N. sativa metabolites, and retaining in mind the fabulous necessity of time for the improvement of powerful antiviral, a joined docking, ADMET characteristics measuring, molecular dynamics, and MMPBSA techniques were operated in the current investigation to scan the healing candidates of $\mathrm{N}$. sativa major compounds versus COVID-19. Among the searched compounds, they detected that dithymoquinone (DTQ), with binding affinity of $8.6 \mathrm{kcal} / \mathrm{mol}$ compared to a positive control (chloroquine, $7.2 \mathrm{kcal} / \mathrm{mol}$ ) , possess the great capacity of binding at SARS-CoV-2:ACE2 interface and hence could be concluded as a probable inhibitor to interrupt viral- host interplays. Molecular dynamics demonstration of $100 \mathrm{~ns}$ fully completed binding affinity of the molecule and disclosed powerful stability of DTQ at the docked pocket. Furthermore, MM-PBSA as well as confirms the docking outcomes. Metabolite DTQ of the current research, if approved in wet lab assays, could be employed to cure COVID-19 and could acts as a hit in the future for progress of more practical natural antivirals versus COVID-19 [171].

Singh and co-workers made a database of polyphenols that possess exhibited substantial healing reactions con different illments. They were well docked in the catalytic cite of RdRp. The research uncovers that EGCG, theaflavin (TF1), theaflavin-3'-0gallate (TF2a), theaflavin-3'-gallate (TF2b), theaflavin 3,3'-digallate (TF3), hesperidin, quercetagetin, and myricetin powerfully connect to the intense pocket of RdRp. Besides, a 150-ns molecular dynamic demonstration disclosed that EGCG, TF2a, TF2b, TF3 outcome in greatly resistant bound conformations with RdRp. The binding free energy contents measured by the MM-PBSA affirm the strength of the complexes too. They likewise carried out a comprehensive examination of ADME prediction, toxicity prediction, and target test for their draggability. Overall, their results propose that EGCG, TF2a, TF2b, TF3 can prevent RdRp and suggest an productive cure for COVID-19 [172]. According to Gyebi et. al.'s research, 62 bioactive alkaloids and 100 terpenoids of herbs native to Africa were docked to the 3CLpro of the novel SARS-CoV-2. The hit twenty alkaloids and terpenoids with powerful binding affinities to the SARS-CoV-2 3CLpro were additional docked to the 3CLpro of SARS-CoV and MERS-CoV. The docking outcomes were compared with 3CLproremarked inhibitors (Lopinavir and Ritonavir). The high docked molecules were then submitted to ADEM/Tox and Lipinski filtering examinations for drug-resemblance assuming examination.

This ligand-protein interaction research disclosed that more than half of the best twenty alkaloids and terpenoids connected desirable with the coronaviruses 3CLpro, and own binding affinities that outpaced that of lopinavir and ritonavir. Besides, a highly characterized top-list of seven metabolites (10-Hydroxyusambarensine, Cryptoquindoline, 6-Oxoisoiguesterin, 22-Hydroxyhopan-3-one, Cryptospirolepine, Isoiguesterin and 20-Epibryonolic acid) were identified. Moreover, four non-toxic, druggable herb derived alkaloids (10-Hydroxyusambarensine, and Cryptoquindoline) and terpenoids (6-0xoisoiguesterin and 22Hydroxyhopan-3-one), that connect to the receptor-binding cavity and catalytic pair of SARS-CoV-2 3CLpro were determined from the predictive ADME/tox and Lipinski filter examination. However, advanced experimental investigations are needed for improving these likely leads into natural anti-COVID-19 curative agents for fighting the pandemic [173]. As mentioned in Al-Sehemi and collegues' publication, Nitric oxide (NO) prevents the duplication cycle of SARS-CoV.

Inhalation of nitric oxide is utilized in the healing of serious acute respiratory syndrome. Herein, they searched the phenyl 
furoxan, a common exogenous NO donor to determine the potential effective inhibitors through in silico analysis like molecular docking as for each target analysis for nominees connect to substrate binding site of SARS-COV-2 M pro. They pictured that spiro-isoquinolinopiperidine-furoxan residues can be exploited as productive ligand for SARS- CoV-2 Mpro inhibition because of the existence of clue isoquinolino-piperidine skeleton with extra NO effect [174]. The recent investigation of Wahedi and co-workers' targeted to repuse stilbenoid derivatives, declared for some other biological actions, con SARS-CoV-2 spike protein and human ACE2 receptor complex for their affinity and durability by molecular dynamics demonstration and binding free energy examination placed on molecular docking. Four molecules all were investigated for their binding affinity utilizing molecular docking. All of the compounds exhibited good affinity (> 7kcal/mol). Nevertheless, fifty nanoseconds molecular dynamic demonstration in aqueous solution disclosed extremely strong bound conformation of resveratrol to the viral protein: ACE2 receptor complex. Net free energy of binding handling MMPBSA as well as affirmed the stability of the resveratrol-protein complex. Stand on the outcomes, they announce that stilbene type compounds in usual and resveratrol, in unusual, can be encouraging anti-COVID-19 medicine nominees serving through interruption of the spike protein. Their data in this research are encouraging and demand advanced in vitro and in vivo assaying of stiblenoids, particularly resveratrol versus the COVID-19 [175].

\section{Conclusion}

In the first part of the review, we have presented different drug combinations using the treatment of COVID-19. When their EC50 values are compared with each others by examining the papers collected, the most satisfying inhibitory effect on SARSCOV-2 belongs to Remdevisir with a EC50 of $0.77 \mu \mathrm{M}$, chloroquine is the second effective drug with EC50 of $1.13 \mu \mathrm{M}$. Concerning the other repurposed drugs, some of them has not been tested on SARS-COV-2 but still using the treatment protocols, some has promising results from their clinical trials is adding the curative protocols, some owns the ongoing clinical trials at the moment of searching the literature survey of this review. The second section of the review is about the candidates of anti-COVID-19 agents. All manuscripts collected the review is based on the measuring these compounds binding and inhibiting capacity of the critical protein molecules about maintaining to be alive of the COVID-19 virus by using the computer programmes i.e in silico researches. Scanning these in silico studies will be a perfect lead source to the in vitro and in vivo investigations respectively.

The natural compounds from different plants (Azadirachta indica, Andrographis paniculata, Glycyrrhiza glabra, Mauritia flexuosa L., Aesculus hippocastanum, Rauwolfia sp.,Panax ginseng, Boenninghausenia sessilicarpa, Lycoris radiata, Stephania japonica, Withania somnifera, Clerodendrum sp.,Asparagus racemosus, green tea, tea plant, Broussonetia papyrifera, calendula officinalis, cinnamon sp., Tinaspora cordifolia, Ammoides verticillata, Nigella sativa) are the mentioned. Except from them, it was also adverted from lots of the in silico research papers about natural compounds such as the flavonoids, alkaloids, saikosaponins, anthocyaninderived compounds, estradiol, essential oil constituents obteined from diffrerent plants, polyphenols, stilbenoid derivatives. Moreover, the in silico manuscripts on the natural compounds isolated from microorganisms (Lactobacillus plantarum, cyanobacterial metabolites) are presented in the review. Finally, it was remarked from some in silico papers about the marketed drugs (Cefuroxim, nitoazoxanide, cobicistat, iopromide, cangrelor, fortovase, hopeaphenol, cyclosieversiodide-A, nitric oxide). When it has been assessed on the basis of their EC50 values, cepharanthine, a bisbenzylisoquinoline alkaloid from tubers of Stephania japonica is the most powerful coronavirus inhibitor with EC50 value of 0.98 $\mathrm{mmol} / \mathrm{L}$. Yet, more in vitro and in vivo researches are needed to be done for reaching the real information about the potent drug candidates of anti-COVID-19.

\section{References}

1. AE Zemlin, OJ Wiese (2020) Coronavirus disease 2019 COVID-19 and the renin-angiotensin system: A closer look at angiotensin-converting enzyme 2 (ACE2). Annals of Clinical Biochemistry 57(5): 339-350.

2. CC Lai, TP Shih, WC Ko, HJ Tang, PR Hsueh (2020) Severe acute respiratory syndrome coronavirus 2 (SARS-CoV-2) and coronavirus disease- 2019 (COVID-19): the epidemic and the challenges. Int J Antimicrob Agents 55(3): 105924.

3. DE Gordon, GM Jang, M Bouhaddou, J Xu, K Obernier, et al. (2020) A SARS-CoV-2 protein interaction map reveals targets for drug repurposin. Nature.

4. Md H Uddin, JA Zonder, AS Azmi (2020) Exportin 1 inhibition as antiviral therapy. Drug Discov Today 25(10): 1775-1781.

5. A Dömling, L Gao (2020) Chemistry and Biology of SARS-CoV-2. Chem 6(6): 1283-1295.

6. World Health Organization.

7. CL Braga, RP Silva Aguiar, D Battaglini, DB Peruchetti, C Robba, et al. (2020) The renin-angiotensin-aldosterone system: Role in pathogenesis and potential therapeutic target in COVID-19. Pharmacol Res Perspect 8(4): e00623.

8. BX Wang, EN Fish (2012) The Yin and Yang of viruses and interferons. Trends Immunol 33(4): 190-197.

9. SD McCarthy, B Majchrzak Kita, T Racine, HN Kozlowski, DP Baker, et al. (2016) A rapid screening assay identifies monotherapy with interferonss and combination therapies with nucleoside analogs as effective inhibitors of Ebola virus. PLoS Negl Trop Dis 10: e0004364.

10. HLL Yang, Ff Liu, Xn Ma, Pl He, W Tang, et al. (2020) Overview of therapeutic drug research for COVID-19 in China. Acta Pharmacologica Sinica 41(9): 1133-1140.

11. JFW Chan, KH Chan, RYT Kao, KKW To, BJ Zheng, et al. (2013) Broadspectrum antivirals for the emerging Middle East respiratory syndrome coronavirus. J Infect 67(6): 606-616.

12. BJ Hart, J Dyall, E Postnikova, H Zhou, J Kindrachuk, et al. (2014) Interferon- $\beta$ and mycophenolic acid are potent inhibitors of Middle East respiratory syndrome coronavirus in cell-based assays. J Gen Virol 95(3): 571-577.

13. MA Martinez (2020) Compounds with therapeutic potential against novel respiratory 2019 coronavirus. Antimicrob Agents Chemother 64: e00399-20. 
14. RS Cvetkovic, KL Goa (2003) Lopinavir/ritonavir: a review of its use in the management of HIV infection. Drugs 63(8): 769-802.

15. TP Sheahan, AC Sims, SR Leist, A Schäfer, J Won, et al. (2020) Comparative therapeutic efficacy of remdesivir and combination lopinavir, ritonavir, and interferon beta against MERS-CoV. Nat Commun 11: 222.

16. Diagnosis and Treatment Protocol for Novel Coronavirus Pneumonia (Trial Version 7) 133(9): 1087-1095.

17. Cao B, Wang Y, Wen D, Liu W, Wang J, et al. (2020) A Trial of LopinavirRitonavir in Adults Hospitalized with Severe Covid-19. N Engl J Med 382: 1787-1799.

18. C Chen, Y Zhang, J Huang, P Yin, Z Cheng, et al. (2020) Favipiravir versus Arbidol for COVID-19: A Randomized Clinical Trial. medRxiv:03.17.20037432.

19. AH de Wilde, D Jochmans, CC Posthuma, JC Zevenhoven Dobbe, S van Nieuwkoop, et al. (2014) Screening of an FDA-approved compound library identifies four small-molecule inhibitors of Middle East respiratory syn- drome coronavirus replication in cell culture. Antimicrob Agents Chemother 58: 4875-4884.

20.X Huang, Y Xu, Q Yang, J Chen, T Zhang, et al. (2015) Efficacy and biological safety of lopinavir/ritonavir based anti-retroviral therapy in HIV-1-infected pa- tients: a meta-analysis of randomized controlled trials. Sci. Rep. 5: 8528.

21. CM Chu, VCC Cheng, IFN Hung, MML Wong, KH Chan, et al. (2004) Role of lopinavir/ritonavir in the treatment of SARS: initial virological and clinical findings. Thorax 59(3): 252-256.

22. YM Arabi, A Alothman, HH Balkhy, A Al Dawood, S AlJohani, et al. (2018) Treatment of Middle East Respiratory Syndrome with a combination of lopinavir- ritonavir and interferon-beta1b (MIRACLE trial): study protocol for a randomized controlled trial. Trials 19: 81

23. EM Mangum, KK Graham (2001) Lopinavir Ritonavir: a new protease inhibitor. Pharmacotherapy 21(11): 1352-1363.

24. F Huang, Y Li, E L H Leung, X Liu, K Liu, et al. (2020) A review of therapeutic agents and Chinese herbal medicines against SARS- COV-2 (COVID-19). Pharmacological Research 158: 104929.

25. B Cao, Y Wang, D Wen, WL W Jingli, G Fan, et al. (2020) A trial of lopinavirritonavir in adults hospitalized with severe covid-19. N Engl J Med 382 1787-1799.

26. Lexicomp Database Online (2016).

27. CM Chu, VCC Cheng, IFN Hung, MML Wong, KH Chan, et al. (2004) Role of lopinavir/ritonavir in the treatment of SARS: initial virological and clinical findings. Thorax 59(3).

28. G Nittari, G Pallotta, F Amenta, SK Tayebati (2020) Current pharmacological treatments for SARS-COV-2: A narrative review. European Journal of Pharmacology 882: 173328.

29. S Beaucourt, M Vignuzzi (2014) Ribavirin: a drug active against many viruses with multiple effects on virus replication and propagation. Molecular basis of ribavirin resistance. Curr Opin Virol 8: 10-15.

30. TP Trang, M Whalen, A Hilts Horeczko, SB Doernberg, C Liu (2018) Comparative effectiveness of aerosolized versus oral ribavirin for the treatment of respiratory syncytial virus infections: a single-center retrospective cohort study and review of the literature. Transpl Infect Dis 20(2): e12844.

31. C Hézode, JP Bronowicki (2016) Ideal oral combinations to eradicate HCV: the role of ribavirin. J Hepatol 64(1): 215-225.

32. N Lee, D Hui, A Wu, P Chan, P Cameron, et al. (2003) A major outbreak of severe acute respiratory syndrome in Hong Kong. N Engl J Med 348(20): 1986-1994.

33. CM Booth, LM Matukas, GA Tomlinson, AR Rachlis, DB Rose, et al. (2003) Clinical features and short-term outcomes of 144 patients with SARS in the greater Toronto area. JAMA 289(21): 2801-2809.
34. J Chan, C Ng, Y Chan, T Mok, S Lee, et al. (2003) Short term outcome and risk factors for adverse clinical outcomes in adults with severe acute respiratory syndrome (SARS). Thorax 58(8): 686-689.

35. J Sung, A Wu, GM Joynt, KY Yuen, N Lee, et al. (2004) Severe acute respiratory syndrome: report of treatment and outcome after a major outbreak. Thorax 59(5): 414-420.

36. B Morgenstern, M Michaelis, PC Baer, HW Doerr, J Cinatl (2005) Ribavirin and interferon- beta synergistically inhibit SARS-associated coronavirus replication in animal and human cell lines. Biochem Biophys Res Commun 326(4): 905-908.

37.J Blaising, SJ Polyak, EI Pécheur (2014) Arbidol as a broad sprctrum antivital: un update. Antiviral Res 107: 84-94.

38. DL McKee, A Sternber, U Stange, S Laufer, C Naujokat (2020) Candidate drugs against SARS-CoV-2 and COVID-19. Pharmacological Research 157: 104859

39. YS Boriskin, IA Leneva, EI Pécheur, SJ Polyak (2008) Arbidol: a broadspectrum antiviral compound that blocks viral fusion. Curr Med Chem 15(10): 997-1005.

40. EI Pécheur, V Borisevich, P Halfmann, JD Morrey, DF Smee, et al. (2016) The synthetic antiviral drug arbidol inhibits globally prevalent pathogenic viruses. J Virol 90(6): 3086-3092.

41. Z Wang, B Yang, Q Li, L Wen, R Zhang (2020) Clinical features of 69 cases with coronavirus disease 2019 in Wuhan, China. Clin Infect Dis 71(15): 769-777.

42. L Deng, C Li, Q Zeng, X Liu, X Li, et al. (2020) Arbidol combined with LPV/r versus LPV/r alone against corona virus disease 2019: a retrospective cohort study. J Infect 81(1): 1-5.

43. NCT04255017 (2020) ClinicalTrials.gov Feb 5.

44. NCT04260594 (2020) ClinicalTrials.gov Feb 7.

45. NCT04273763 (2020) ClinicalTrials.gov Feb 18.

46. NCT04286503 (2020) ClinicalTrials.gov Feb 27.

47. Y Furuta, K Takahashi, Y Fukuda, M Kuno, T Kamiyama, et al. (2020) In vitro and in vivo activities of anti-influenza virus compound T-705. Antimicrob Agents Chemother 46(4): 977-981.

48. Y Furuta, T Komeno, T Nakamura (2017) Favipiravir (T-705), A broad spectrum in- hibitor of viral RNA polymerase. Proc Jpn Acad Ser B Phys Biol Sci 93(7): 449-463.

49. Z Jin, LK Smith, VK Rajwanshi, B Kim, J Deval (2014) The ambiguous basepairing and high substrate efficiency of T-705 (favipiravir) ribofuranosyl 5'-triphosphate towards influenza A virus polymerase. PLoS One 8(7): e68347.

50.E De Clercq (2013) Dancing with chemical formulae of antivirals: a personal account. Biochem Pharmacol 86(6): 711-725.

51.E De Clercq (2013) Dancing with chemical formulae of antivirals: A panoramic view (Part 2). Biochem Pharmacol 86(10): 1397-1410.

52. Y Furuta, K Takahashi, M Kuno Maekawa, H Sangawa, S Uehara, et al (2005) Mechanism of action of T-705 against influenza virus. Antimicrob Agents Chemother 49(3): 981-986.

53.E De Clercq (2019) New nucleoside analogues for the treatment of hemorrhagic fever virus infections. Chem-Asian J 14(22): 3962-3968.

54. Wang M, Cao R, Zhang L, Yang X, Liu J, et al. (2020) Remdesivir and chloroquine effectively inhibit the recently emerged novel coronavirus (2019-nCoV) in vitro. Cell Res 30(3): 269-271.

55. R Lu, X Zhao, J Li, P Niu, B Yang, et al. (2020) Genomic characterisation and epidemiology of novel coronavirus: implications for virus origins and receptor binding. Lancet 395(10224): 565-574.

56. G Li, E De Clercq (2020) Therapeutic options for the 2019 novel coronavirus (2019-nCoV). Nat Rev Drug Discov 19(3): 149-150. 
57. F Menzella, M Biava, C Barbieri, F Livrieri, N Facciolongo (2020) Pharmacological treatment of COVID-19: lights and shadows. Drugs in Context 9: 4-6.

58. MK Lo, R Jordan, A Arvey, J Sudhamsu, P Shrivastava Ranjan, et al. (2017) GS-5734 and its parent nucleoside analog inhibit filo-, pneumo-, and paramyxoviruses. Sci Rep 7(1): 43395.

59. TP Sheahan, AC Sims, RL Graham, VD Menachery, LE Gralinski, et al. (2017) Broad-spectrum antiviral GS-5734 inhibits both epidemic and zoonotic coronaviruses. Sci Transl Med 9(396): eaal3653.

60. ML Agostini, EL Andres, AC Sims, RL Graham, TP Sheahan, et al. (2018) Coronavirus susceptibility to the antiviral remdesivir (GS-5734) is mediated by the viral polymerase and the proofreading exoribonuclease. mBio 9(2): e00221-18.

61. S Mulangu, LE Dodd, RT Davey, O Tshiani Mbaya, M Proschan, etal. (2019) A randomized, controlled trial of Ebola virus disease therapeutics. N Engl J Med 381: 2293-2303.

62. T Cihlar, AS Ray (2010) Nucleoside and nucleotide HIV reverse transcriptase inhibitors: 25 years after zidovudine. Antivir Res 85(1): 39-58.

63. AA Eltahla, F Luciani, PA White, AR Lloyd, RA Bull (2015) Inhibitors of the hepatitis $C$ virus polymerase; mode of action and resistance. Viruses $7(10):$ 5206-5224.

64. EP Tchesnokov, JY Feng, DP Porter, M Gotte (2019) Mechanism of inhibition of Ebola virus RNA-dependent RNA polymerase by remdesivir Viruses 11(4): 326.

65. ML Holshue, C DeBolt, S Lindquist, KH Lofy, J Wiesman, et al. (2020) First case of 2019 novel Coronavirus in the United States. N Engl J Med 382(10): 929-936.

66. TP Sheahan, AC Sims, RL Graham, VD Menachery, LE Gralinski, et al. (2017) Broad-spectrum antiviral GS- 5734 inhibits both epidemic and zoonotic coronaviruses. Sci transl Med 9(396).

67. WC Ko, JM Rolain, NY Lee, PL Chen, CT Huang, et al. (2020) Arguments in favour of remdesivir for treating SARS-CoV-2 infections. Int J Antimicrob Agents 55(4): 105933

68. F Barati, M Pouresmaieli, E Ekrami, S Asghari, FR Ziarani, et al. (2020) Potential Drugs and Remedies for the Treatment of COVID-19: a Critical Review Barati et al. Biological Procedures Online 22: 15

69. I Ben Zvi, S Kivity, P Langevitz, Y Shoenfeld (2012) Hydroxychloroquine: from malaria to autoimmunity. Clin Rev Allergy Immunol 42(2): 145153.

70. A Savarino, L Di Trani, I Donatelli, R Cauda, A Cassone (2006) New insights into the antiviral effects of chloroquine. Lancet Infect Dis 6(2): 67-69.

71. Y Yan, Z Zou, Y Sun, X Li, KF Xu, et al. (2013) Anti-malaria drug chloroquine is highly effective in treating avian influenza A H5N1 virus infection in an animal model. Cell Res 32(2): 300-302.

72. A Savarino (2011) Use of chloroquine in viral diseases. Lancet Infect Dis 11(9): 653-654.

73. A Savarino, JR Boelaert, A Cassone, G Majori, R Cauda (2003) Effects of chloroquine on viral infections: an old drug against today's diseases? Lancet Infect Dis 3(11): 722-777.

74. AH de Wilde, EJ Snijder, M Kikkert, MJ van Hemert (2018) Host factors in coronavirus replication. Curr Top Microbiol Immunol 419: 1-42.

75. F Li (2012) Evidence for a common evolutionary origin of coronavirus spike protein receptor-binding subunits. J Virol 86(5): 2856-2858.

76. MJ Vincent, E Bergeron, S Benjannet, BR Erickson, PE Rollin, et al. (2005) Chloroquine is a potent inhibitor of SARS coronavirus infection and spread. Virol J 2: 69.

77. M Frisk Holmberg, Y Bergqvist, Englund U (1983) Chloroquine intoxication [letter]. Br J Clin Pharmacol 15(4): 502-503.
78. A Chauhan, A Tikoo (2015) The enigma of the clandestine association between chloroquine and HIV-1 infection. HIV Med 16(10): 585-590.

79. GK Helal, MA Gad, MF Abd Ellah, M Saied Eid (2016) Hydroxychloroquine augments early virological response to pegylated interferon plus ribavirin in genotype-4 chronic hepatitis C patients. J Med Virol 88(12): 2170-2178.

80. CA Devaux, JM Rolain, P Colson, D Raoult (2020) New insights on the antiviral effects of chloroquine against coronavirus: what to expect for COVID-19? Int J Antimicrob Agents 55(5): 105938.

81. MJ Vincent, E Bergeron, S Benjannet, BR Erickson, PE Rollin, et al. (2005) Chloroquine is a potent inhibitor of SARS coronavirus infection and spread. Virol J 2: 69 .

82. M Wang, R Cao, L Zhang, X Yang, J Liu, et al. (2020) Remdesivir and chloroquine effectively inhibit the recently emerged novel coronavirus (2019-nCoV) in vitro. Cell Res 30(3): 269-271.

83. Sk A Amin, T Jha (2020) Fight against novel coronavirus: A perspective of medicinal chemists. European Journal of Medicinal Chemistry 201: 112559

84.J Gao, Z Tian, X Yang (2020) Breakthrough: chloroquine phosphate has shown apparent efficacy in treatment of COVID-19 associated pneumonia in clinical studies. Biosci Trends 14(1): 72-73.

85. L Delang, J Neyts (2020) Medical treatment options for COVID-19. European Heart Journal: Acute Cardiovascular Care 9(3): 209-214.

86. KD Rainsford, AL Parke, M Clifford Rashotte, WF Kean (2015) Therapy and pharmaco- logical properties of hydroxychloroquine and chloroquine in treatment of sys- temic lupus erythematosus, rheumatoid arthritis and related diseases. Inflammopharmacology 23(5): 231-269.

87. C Biot, W Daher, N Chavain, T Fandeur, J Khalife, et al. (2006) Design and synthesis of hydroxyferroquine derivatives with antimalarial and antiviral activities. J Med Chem 49(9): 2845-2849.

88. X Yao, F Ye, M Zhang, C Cui, B Huang, et al. (2020) In vitro antiviral activity and projection of optimized dosing design of hydroxychloroquine for the treatment of severe acute respiratory syndrome Coronavirus 2 (SARSCoV-2). Clin Infect Dis 71(15): 732-739.

89. MF Marmor, U Kellner, TYY Lai, RB Melles, WF Mieler (2016) Recommendations onScreeningforChloroquineand Hydroxychloroquine Retinopathy (2016 Revision). Ophthalmology 123(6): 1386-1394.

90. P Gautret, JC Lagier, P Parola, VT Hoang, L Meddeb, et al. (2020) Hydroxychloroquine and azithromycin as a treatment of COVID-19: results of an open-label non-randomized clinical trial. Int J Antimicrob Agents 56(1): 105949.

91.Z Chen, J Hu, Z Zhang, S Jiang, S Han, et al. (2020) Efficacy of hydroxychloroquine in patients with COVID-19: results of a randomized clinical trial. medRxiv: 20040758

92. A Crump (2017) Ivermectin: enigmatic multifaceted "wonder" drug continues to surprise and exceed expectations. J Antibiot (Tokyo) 70(5): 495-505.

93. KM Wagstaff, H Sivakumaran, SM Heaton, D Harrich, DA Jans (2012) Ivermectin is a specific inhibitor of importin $\alpha / \beta$-mediated nuclear import able to inhibit replication of HIV-1 and dengue virus. Biochem J 443 (3): 851-856

94. L Caly, KM Wagstaff, DA Jans (2012) Nuclear trafficking of proteins from RNA viruses: potential target for antivirals? Antivir. Res 95(3): 202-206.

95. L Caly, JD Druce, MG Catton, DA Jans, KM Wagstaff (2020) The FDAapproved drug ivermectin inhibits the replication of SARS-CoV-2 in vitro. Antivir. Res 178: 104787.

96. M Sheppard, F Laskou, PP Stapleton, S Hadavi, B Dasgupta (2017) Tocilizumab (actemra). HumVaccines Immunother 13(9).

97. X Xu, M Han, T Li, W Sun, D Wang, et al. (2020) Effective Treatment of Severe COVID-19 Patients with Tocilizumab. chinaXiv 117(20): 1097010975. 
98. LJ Scott (2017) Sarilumab: first global approval. Drugs 77(6): 705-712.

99. YN Lamb, ED Deeks (2018) Sarilumab: a review in moderate to severe rheumatoid arthritis. Drugs 78(9): 929-940.

100. C Ma, MD Sacco, B Hurst, JA Townsend, Y Hu, et al. (2020) GC-376, and calpain inhibitors II, XII inhibit SARS-CoV-2 viral replication by targeting the viral main protease. Cell Research 30: 678-692.

101. H Ulrich, MM Pillat (2020) CD147 as a Target for COVID-19 Treatment: Suggested Effects of Azithromycin and Stem Cell Engagement. Stem Cell Reviews and Reports 16(3): 434-440.

102. X Zhang, Y Zhang, W Qiao, J Zhang, Z Qi (2020) Baricitinib a drug with potential effect to prevent SARS-COV-2 from entering target cells and control cytokine storm induced by COVID-19. International Immunopharmacology 86: 106749.

103. S Borkotoky, M Banerjee (2020) A computational prediction of SARSCoV-2 structural protein inhibitors from Azadirachta indica (Neem) Subhomoi Borkotoky and Manidipa Banerjee. Journal of Biomolecular Structure And Dynamics : 1-11.

104. L Sarkar, RK Putchala, AA Safiriyu, JD Sarma (2020) Azadirachta indica A Juss ameliorates mouse hepatitis virus-induced neuroinflam- matory demyelination by modulating cell-to-cell fusion in an experi- mental animal model of multiple sclerosis. Frontiers in Cellular Neuroscience 14: 116

105. R Islam, R Parves, AS Paul, N Uddin, S Rahman, et al. (2020) A molecular modeling approach to identify effective antiviral phytochemicals against the main protease of SARS-CoV-2. Journal Of Biomolecular Structure And Dynamics : 1-12.

106. SK Sinha, A Shakya, SK Prasad, S Singh, NS Gurav, et al. (2020) An insilico evaluation of different Saikosaponins for their potency against SARS-CoV-2 using NSP15 and fusion spike glycoprotein as targets, Journal Of Biomolecular Structure And Dynamics.

107. S Kumar Enmozhi, K Raja, I Sebastine, J Joseph (2020) Andrographolide as a potential inhibitor of SARS-CoV-2 main protease: an in silico approach. Journal Of Biomolecular Structure And Dynamics: 1-7.

108. LE Rojo, D Ribnicky, S Logendra, A Poulev, P Rojas Silva, et al. (2012) In vitro and in vivo anti-diabetic effects of anthocyanins from Maqui Berry (Aristotelia chilensis). Food Chemistry 131(2): 387-396.

109. K Hosokawa, E Fukushi, J Kawabata, C Fujii, T Ito, et al. (1997) Seven acylated anthocyanins in blue flowers of Gentiana. Phytochemistry 45(1): $167-171$.

110. M Maeda Yamamoto, T Saito, A Nesumi, Y Tokuda, K Ema, et al (2012) Chemical analysis and acetylcholinesterase inhibitory effect of anthocyanin-rich red leaf tea (cv. Sunrouge). Journal of the Science of Food and Agriculture 92(11): 2379-2386.

111. DS Wishart, C Knox, AC Guo, R Eisner, N Young, et al. (2009) HMDB: A knowledgebase for the human metabolome. Nucleic Acids Research 37: D603-D610.

112. DS Wishart, D Tzur, C Knox, R Eisner, AC Guo, et al. (2007) HMDB: The Human Metabolome Database. Nucleic Acids Research 35: D521-D526.

113. OP Johansen, ØM Andersen, W Nerdal, DW Aksnes (1991) Cyanidin 3-[6-(p-coumaroyl)-2-(xylosyl)-glucoside]-5-glucoside and other anthocyanins from fruits of sambucus canadensis. Phytochemistry 30(12): 4137-4141.

114. Z Fakhar, B Faramarzi, S Pacifico, S Faramarzi (2020) Anthocyanin derivatives as potent inhibitors of SARS-CoV-2 main protease: An insilico perspective of therapeutic targets against COVID-19 pandemic. Journal Of Biomolecular Structure And Dynamics p. 1-13.

115. I Aanouz, A Belhassan, K El Khatabi, T Lakhlifi, M El Idrissi, et al. (2020) Moroccan medicinal plants as inhibitors of COVID-19: Computational investigations. Journal of Biomolecular Structure \& Dynamics 6: 1-9.

116. F Anwar, HN Altayb, FA Al Abbasi, AL Al Malki, MA Kamal, et al. (2020) Antiviral effects of probiotic metabolites on COVID-19. Journal of Biomolecular Structure And Dynamics.
117. AN Costa, ERA de Sa, RDS Bezerra, JL Souza, F das CA Lima (2020) Constituents of buriti oil (Mauritia flexuosa L.) like inhibitors of the SARS-Coronavirus main peptidase: an investigation by docking and molecular Dynamics. Journal Of Biomolecular Structure And Dynamics p. 1-8.

118. AB Durojaiye, JR D Clarke, GA Stamatiades, C Wang (2020) Repurposing cefuroxime for treatment of COVID-19: a scoping review of in silico studies. Journal Of Biomolecular Structure And Dynamics p. 1-8.

119. J Galvez, R Zanni, M Galvez Llompart (2020) Drugs repurposing for coronavirus treatment: Computational study based on molecular topology. Nereis. Interdisciplinary Ibero-American Journal of Methods, Modelling and Simulation.

120. J Galvez, M Galvez Llompart, R Garcia Domenech (2012) Molecular topology as a novel approach for drug discovery. Expert Opinion on Drug Discovery 7(2): 133-153.

121. CJ Almeciga Diaz, LN Pimentel Vera, A Caro, A Mosquera, CAC Moreno, et al. (2020) Virtual screening of potential inhibitors for SARS-CoV-2 main protease. Preprints.

122. CJ Almeciga Diaz, OA Hidalgo, S Olarte Avellaneda, A Rodriguez Lopez, E Guzman, et al. (2019) Identification of ezetimibe and pranlukast as pharmacological chaper- ones for the treatment of the rare disease mucopolysaccharidosis Type Iva. Journal of Medicinal Chemistry 62(13): 6175-6189.

123. S Koulgi, V Jani, M Uppuladinne, U Sonavane, AK Nath, et al. (2020) Drug repurposing studies tar- geting SARS-nCoV2: An ensemble docking approach on drug target 3C-like protease (3CLpro). ChemRxiv Preprint.

124. K Al Khafaji, LD Al Duhaidahawi, T Taskin Tok (2020) Using integrated computational approaches to identify safe and rapid treatment for SARS-CoV-2. Journal of Biomolecular Structure and Dynamics.

125. W Dai, B Zhang, H Su, J Li, Y Zhao, et al. (2020) Structure-based design of antiviral drug candidates targeting the SARS-CoV-2 main protease. Science 368(6497): 1331-1335.

126. X Xue, H Yu, H Yang, F Xue, Z Wu, et al. (2008) Structures of two coronavirus main proteases: Implications for sub- strate binding and antiviral drug design. Journal of Virology 82(5): 2515-2527.

127. L Zhang, D Lin, X Sun, U Curth, C Drosten, et al. (2020) Crystal structure of SARS-CoV-2 main protease provides a basis for design of improved a-ketoamide inhibitors. Science 368(6489): 409-412.

128. C Wu, Y Liu, Y Yang, P Zhang, W Zhong, et al. (2020) Analysis of therapeutic targets for SARS-CoV-2 and discovery of potential drugs by computational methods. Acta Pharmaceutica Sinica B 10(5): 766-788.

129. R Abagyan, A Orry, E Raush, M Totrov (2020) Icm-Pro user guide V. 3.8. Molsoft, LLC.

130. I Muegge, YC Martin (1999) A general and fast scoring function for protein-ligand interactions: A simplified potential approach. Journal of Medicinal Chemistry 42(5): 791-804.

131. MA Neves, M Totrov, R Abagyan (2012) Docking and scoring with ICM: The benchmarking results and strategies for improvement. Journal of Computer-Aided Molecular Design 26(6): 675-686.

132. AA Elfiky (2020) SARS-CoV-2 RNA Dependent RNA Polymerase (Rdrp) targeting: An in silico perspective. Journal of Biomolecular Structure \& Dynamics p. 1-9.

133. SR Darya, SS MacKinnon, M Landon, A Windemuth, N Kurji, et al. (2020) PolypharmDB, a deep learning-based resource, quickly identifies repurposed drug candidates for Covid-19. ChemRxiv. Preprint.

134. AC Breithaupt Faloppa, C de Jesus Correia, CM Prado, RS Stilhano, RP Ureshino, et al. (2020) 17b-Estradiol, a potential ally to alleviate SARSCoV- 2 infection. CLINICS 75: e1980.

135. J Kelly, R da Silva, PLB Figueiredo, KG Byler, WN Setzer (2020) Essential Oils as Antiviral Agents, Potential of Essential Oils to Treat SARS-CoV-2 Infection: An In-Silico Investigation. Int J Mol Sci 21(10): 3426. 
136. (2020) Redeploying plant defences. Nat Plants 6(3): 177.

137. G Hoever, L Baltina, M Michaelis, R Kondratenko, L Baltina, et al. (2005) Antiviral activity of glycyrrhizic acid derivatives against SARScoronavirus. J Med Chem 48(4):1256-1259.

138. F Wu, W Huang (2020) COVID-19 diagnostic process in mainland China: The math beyond pneumonia J Allergy Clin Immunol 146(1): 64-66.

139. H Ding, W Deng, L Ding, X Ye, S Yin, et al. (2020) Glycyrrhetinic acid and its derivatives as potential alternative medicine to relieve symptoms in nonhospitalized COVID-19 patients. J Med Virol p. 1-5.

140. SK Sinha, SK Prasad, A Islam, SS Guray, RB Patil, et al. (2020) Identification of bioactive compounds from Glycyrrhiza glabra as possible inhibitor of SARS-CoV-2 spike glycoprotein and non-structural protein-15: a pharmacoinformatics study. Journal of Biomolecular Structure and Dynamics p. 1-15.

141. S Padmanabhan (2020) Potential dual therapeutic approach against SARS-Cov-2/COviD-19 with nitazoxanide and hydroxychloroquine.

142. JF Rossignol (2016) Nitazoxanide, a new drug candidate for the treatment of Middle east respiratory syndrome coronavirus. J Infect Public Health 9(3): 227-230.

143. T Pepperrell, V Pilkington, A Owen, J Wang , AM Hill (2020) Review of safety and minimum pricing of nitazoxanide for potential treatment of COVID-19. Journal of Virus Eradication 6(2): 52-60.

144. FDA (2004) Approval of nitazoxanide. Department of Health and Human Services.

145. A Hill, J Wang, J Levi, K Heath, J Fortunak (2020) Minimum costs to manufacture new treatments for COVID-19. J Virus Erad 6(2): 61-69.

146. FE Chen, J Huang (2005) Reserpine: a challenge for total synthesis of natural products. Chem Rev 105(12): 4671-4706.

147. CY Wu, JT Jan, SH Ma, CJ Kuo, HF Juan, et al. (2004) Small molecules targeting severe acute respiratory syndrome human coronavirus. Proc Natl Acad Sci U S A 101(27): $10012 \mathrm{e} 7$.

148. CS Jeong, JE Hyun, YS Kim (2003) Ginsenoside Rb1: the anti-ulcer constituent from the head of Panax ginseng. Arch Pharm Res (Seoul) 26(11): 906-911.

149. QY Yang, XY Tian, WS Fang (2007) Bioactive coumarins from Boenninghausenia sessilicarpa. J Asian Nat Prod Res 9(1): 59-65.

150. SY Li, C Chen, HQ Zhang, HY Guo, H Wang, et al. (2005) Identification of natural compounds with antiviral activities against SARS-associated coronavirus. Antivir Res 67(1): 18-23.

151. HH Fan, LQ Wang, WL Liu, XP An, ZD Liu, et al. (2020) Repurposing of clinically approved drugs for treatment of corona- virus disease 2019 in a 2019-novel coronavirus-related coronavirus model. Chin Med J 133(9): 1051-1056.

152. X Yanfang, J Zhang, Z Bian, H Zhou, Z Zhang, et al. (2020) Bioactive natural compounds against human coronaviruses: a review and perspective. Acta Pharmaceutica Sinica B 10(7): 1163-1174.

153. V Kumar,JK Dhanjal, P Bhargava, A Kaul, JWang, et al. (2020) Withanone and Withaferin-A are predicted to interact with transmembrane protease serine 2 (TMPRSS2) and block entry of SARS-CoV-2 into cells. Journal Of Biomolecular Structure And Dynamics p. 1-13.

154. V Kumar, JK Dhanjal, SC Kaul, R Wadhwa, D Sundar (2020) Withanone and caffeic acid phenethyl ester are predicted to interact with main protease (Mpro) of SARS-CoV-2 and inhibit its activity. Journal of Biomolecular Structure And Dynamics p. 1-13.

155. AR Straughn, SS Kakar (2020) Withaferin A: a potential therapeutic agent against COVID-19 infection. Journal of Ovarian Research 13(79).

156. MK Tripathi, P Singh, S Sharma, TP Singh, AS Ethayathulla, et al (2020) Identification of bioactive molecule from Withania somnifera
(Ashwagandha) as SARS-CoV-2 main protease inhibitör. Journal of Biomolecular Structure And Dynamics.

157. RV Chikhale, SS Gurav, RB Patil, SK Sinha, SK Prasad, et al. (2020) Sarscov-2 host entry and replication inhibitors from Indian ginseng: an in-silico approach, Journal Of Biomolecular Structure And Dynamics p. 1-12.

158. P Kar, NR Sharma, B Singh, A Sen, A Roy (2020) Natural compounds from Clerodendrum spp. as possible therapeutic candidates against SARS-CoV-2: An in silico investigation. Journal of Biomolecular Structure And Dynamics p. 1-10.

159. RV Chikhale, SK Sinha, RB Patil, SK Prasad, A Shakya, et al. (2020) In-silico investigation of phytochemicals from Asparagus racemosus as plausible antiviral agent in COVID-19. Journal of Biomolecular Structure And Dynamics: 1-15.

160. D Naidoo, A Roy, P Kar, T Mutanda, A Anandraj (2020) Cyanobacterial metabolites as promising drug leads against the Mpro and PLpro of SARS-CoV-2: an in silico analysis. Journal of Biomolecular Structure And Dynamics p. 1-13.

161. R Ghosh, A Chakraborty, A Biswas, S Chowdhuri (2020) Evaluation of green tea polyphenols as novel corona virus (SARS CoV-2) main protease (Mpro) inhibitors - an in silico docking and molecular dynamics simulation study. Journal of Biomolecular Structure And Dynamics p. 1-13.

162. S Jo, S Kim, DY Kim, MS Kim, DH Shin (2020) Flavonoids with inhibitory activity against SARS-CoV-2 3Clpro. Journal Of Enzyme Inhıbıtıon And Medicinal Chemıstry 35(1): 1539-1544.

163. VK Bhardwaj, R Singh, J Sharma, V Rajendran, R Purohit, et al. (2020) Identification of bioactive molecules from tea plant as SARS-CoV-2 main protease inhibitors. Journal of Biomolecular Structure And Dynamics p. 1-10.

164. A Kumar, G Choudhir, SK Shukla, M Sharma, P Tyagi, et al. (2020) Identification of phytochemical inhibitors against main protease of COVID-19 using molecular modeling approaches. Journal of Biomolecular Structure And Dynamics p. 1-11.

165. R Ghosh, A Chakraborty, A Biswas, S Chowdhuri (2020) Identification of polyphenols from Broussonetia papyrifera as SARS CoV-2 main protease inhibitors using in silico docking and molecular Dynamics simulation approaches. Journal of Biomolecular Structure And Dynamics : 1-14.

166. P Sharma, V Vijayan, P Pant, M Sharma, N Vikram, et al. (2020) Identification of potential drug candidates to combat COVID-19: a structural study using the main protease (mpro) of SARS-CoV-2. Journal Of Biomolecular Structure And Dynamics p. 1-11.

167. P Das, R Majumder, M Mandal, P Basak (2020) In-Silico approach for identification of effective and stable inhibitors for COVID-19 main protease (Mpro) from flavonoid based phytochemical constituents of Calendula officinalis. Journal Of Biomolecular Structure And Dynamics p. 1-16.

168. DSN B K Prasanth, M Murahari, V Chandramohan, SP Panda, LR Atmakuri, et al. (2020) In silico identification of potential inhibitors from Cinnamon against main protease and spike glycoprotein of SARS CoV-2. Journal Of Biomolecular Structure And Dynamics p. 1-15.

169. P Chowdhury (2020) In silico investigation of phytoconstituents from Indian medicinal herb 'Tinospora cordifolia (giloy)' against SARS-CoV-2 (COVID-19) by molecular dynamics approach. Journal of Biomolecular Structure And Dynamics p. 1-18.

170. I Abdelli, F Hassani, SB Brikci, S Ghalem (2020) In silico study the inhibition of angiotensin converting enzyme 2 receptor of COVID-19 by Ammoides verticillata components harvested from Western Algeria Journal Of Biomolecular Structure And Dynamics p. 1-14.

171. S Ahmad, HW Abbasi, S Shahid, S Gul, SW Abbasi (2020) Molecular docking, simulation and MM-PBSA studies of nigella sativa compounds: 
a computational quest to identify potential natural antiviral for COVID-19 treatment. Journal Of Biomolecular Structure And Dynamics p. 1-9.

172. S Singh FSK, A Sonawane, P Kar, S Sadhukhan (2020) Plant-derived natural polyphenols as potential antiviral drugs against SARS-CoV-2 via RNA-dependent RNA polymerase (RdRp) inhibition: an in-silico analysis. Journal Of Biomolecular Structure And Dynamics p. 1-16.

173. GA Gyebi, OB Ogunro, AP Adegunloye, OM Ogunyemi, SO Afolabi (2020) Potential inhibitors of coronavirus 3-chymotrypsin-like protease (3CLpro): an in silico screening of alkaloids and terpenoids

ISSN: 2574-1241

DOI: $10.26717 /$ BJSTR.2020.32.005318

Sibel Avunduk. Biomed J Sci \& Tech Res

(C) (P) This work is licensed under Creative Commons Attribution 4.0 License

Submission Link: https://biomedres.us/submit-manuscript.php from African medicinal plants. Journal Of Biomolecular Structure And Dynamics p. 1-13.

174. AG Al Sehemi, M Pannipara, RS Parulekar, O Patil, PB Choudhari, et al. (2020) Potential of NO donor furoxan as SARS-CoV-2 main protease (Mpro) inhibitors: in silico analysis. Journal Of Biomolecular Structure And Dynamics 8: 1-15.

175. HM Wahedi, S Ahmad, SW Abbasi (2020) Stilbene-based natural compounds as promising drug candidates against COVID-19. Journal Of Biomolecular Structure And Dynamics p. 1-10.

$\begin{array}{ll}\text { BIOMEDICAL } & \text { Assets of Publishing with us } \\ \text { RESEARCHES } & \text { - Global archiving of articles } \\ \text { - Immediate, unrestricted online access } & \text { - Rigorous Peer Review Process } \\ & \text { - Authors Retain Copyrights } \\ \end{array}$

